NASA Technical Memorandum 102292

AIAA-89-2583

\title{
Low-Speed Wind Tunnel Performance of High-Speed Counterrotation Propellers at Angle-of-Attack
}

Christopher E. Hughes

National Aeronautics and Space Administration

Lewis Research Center

Cleveland, Ohio

and

John A. Gazzaniga

Sverdrup Technology, Inc.

NASA Lewis Research Center Group

Cleveland, Ohio

Prepared for the

25th Joint Propulsion Conference

cosponsored by the AIAA, ASME, SAE, and ASEE

Monterey, California, July 10-12, 1989

\section{NMS}




\title{
LOW-SPEED WIND TUNNEL PERFORMANCE OF HIGH-SPEED
}

\author{
COUNTERROTATION PROPELLERS AT ANGLE-OF-ATTACK \\ Christopher E. Hughes \\ National Aeronautics and Space Administration \\ Lewis Research Center \\ Cleveland, Ohio 44135
}

and

John A. Gazzaniga

Sverdrup Technology, Inc.

NASA Lewis Research Center Group

Cleveland, Ohio 44135

\begin{abstract}
SUMMARY
The low-speed aerodynamic performance characteristics of two advanced counterrotation pusher-propeller configurations with cruise design Mach numbers of 0.72 were investigated in the NASA Lewis 9- by 15-Foot Low-Speed Wind Tunnel. The tests were conducted at Mach number 0.20 , which is representative of the aircraft takeoff/landing flight regime. The investigation determined the effect of nonuniform inflow on the propeller performance characteristics for several blade angle settings and a range of rotational speeds. The inflow was varied by yawing the propeller model to angle-of-attack by as much as $+16^{\circ}$ and by installing on the counterrotation propeller test rig near the propeller rotors a model simulator of an aircraft engine support pylon and fuselage.

The results of the investigation indicated that the low-speed performance of the counterrotation propeller configurations near the takeoff target operating points were reasonable and were fairly insensitive to changes in model angle-of-attack without the aircraft pylon/fuselage simulators installed on the propeller test rig. When the aircraft pylon/fuselage simulators were installed, small changes in propeller performance were seen at zero angle-of-attack, but fairly large changes in total power coefficient and very large changes of aftto-forward-rotor torque ratio were produced when the propeller model was taken to angle-of-attack. The propeller net efficiency, though, was fairly insensitive to any changes in the propeller flowfield conditions near the takeoff target operating points.
\end{abstract}

\section{INTRODUCTION}

Over the last several years, NASA and industry have been developing and demonstrating the advantages of the advanced high-speed propeller for aircraft propulsion over the more conventional turbofan engine (ref. 1). The high efficiency advantage of the advanced high-speed propeller has been recently demonstrated in scale model wind tunnel tests of single-rotation and counterrotation propellers, both at high-speed and low-speed conditions (refs. 2 to 5). The advanced turboprop propulsion system offers the potential for high propulsive efficiency. Figure 1 is a comparison of the installed propulsive efficiency of several different types of propulsion systems over a range of cruise flight 
Mach numbers. As can be seen, the turboprop offers improved performance over the conventional turbofan at all flight speeds. At high flight Mach numbers, the advanced turboprop overcomes the deficiencies of the conventional turboprop system, maintaining high efficiency to at least Mach number 0.80 . In addition, the more novel advanced technology approaches, such as a single-rotation propeller with swirl recovery vanes or counterrotation propellers, offer further improvements in propeller propulsion performance.

A summary of several NASA and industry studies (ref. 6) to evaluate the potential of advanced high-speed turboprop propulsion is presented in figure 2 . The figure shows the potential block fuel savings of an advanced turboprop propulsion system as a function of the trip stage length. As can be seen in the figure, large fuel savings are possible with the advanced turboprop propulsion system at all stage lengths, especially at the shorter operating ranges. Since the shorter stage lengths are climb and descent dominant, the lower flight velocities can provide the turboprop with an even larger advantage over the turbofan than at cruise flight conditions. The advantages of using advanced propellers in alrcraft propulsion systems has recently been demonstrated with the near full-scale NASA Lewis propeller test assessment (PTA) (fig. 3(a)) and NASA/GE unducted fan (UDF) flight test programs (figs. $3(b)$ and $3(c)$ ).

In support of the NASA Lewis Research Center Advanced Turboprop Program to establish an advanced turboprop technology base, an investigation of the low-speed characteristics of several advanced high-speed counterrotation propeller configurations was conducted in the NASA Lewis 9- by 15-Foot Low Speed Wind Tunnel. The counterrotation propellers were pusher-type designs incorporating a high number of blades, from 16 to 20 total, with very high power loadings. The investigation determined the aerodynamic and aeroacoustic propeller performance of the several counterrotation propeller configurations in the take-offllanding flight regime. This paper presents a summary of the wind tunnel aerodynamic performance results for two of those counterrotation propeller configurations, including propeller performance characteristics with nonuniform inflow in the propeller-model plane of rotation.

NOMENCLATURE

$A_{A} \quad$ propeller annulus area, $\mathrm{ft}^{2}$

AF blade Activity Factor, $6250 \int_{(r / R)_{h u b}}^{1.0}(b / 0)(r / R)^{3} d(r / R)$

$d(r / R)$ elemental radius ratio

b elemental blade chord, ft

D propeller diameter, ft

$J$ advance ratio, $V / n D$

M Mach number

n rotational speed, rps 


$\begin{array}{ll}P & \text { power } \\ P Q A & \text { power coefficient, } 550 \mathrm{SHP} / \mathrm{\rho n}{ }^{3} \mathrm{D}^{3} \mathrm{~A} A \\ R & \text { propeller radius, } \mathrm{ft} \\ r & \text { elemental blade radius, } \mathrm{ft} \\ \text { SHP } & \text { shaft horsepower } \\ T & \text { thrust, } 1 \mathrm{~b} \\ \text { TQA } & \text { thrust coefficient, } T / \rho \mathrm{N}^{2} \mathrm{D}^{2} \mathrm{~A}_{\mathrm{A}} \\ V & \text { velocity, fps } \\ \alpha & \text { propeller model angle-of-attack, deg } \\ n & \text { propeller efficiency, } T(V / P) \\ \rho & \text { air density, slugs } / \mathrm{ft} \mathrm{t}^{3}\end{array}$

\section{Subscripts:}$$
\text { C }
$$

corrected condition

total

0 freestream condition

1 forward propeller rotor

2 aft propeller rotor

MODEL TEST PROGRAM

Wind Tunnel

The propeller model test program was carried out in the NASA Lewis 9- by 15-Foot Low-Speed Wind Tunnel (ref. 7). A schematic of the wind tunnel is shown in figure 4 . The test section is located in the back leg of the 8- by 6-Foot Supersonic Wind Tunnel and is capable of speeds up to Mach number 0.23 . The test section has slotted walls to minimize any model interaction with the tunnel walls, and has been acoustically treated to allow propeller noise measurement.

\section{Propeller Test Rig}

The model counterrotation propeller test rig (CRP/PTR) used in the investigation was designed to simulate a counterrotating propulsion system in a pusher-propeller configuration. A photograph of the CRP/PTR installed in the NASA Lewis 9- by 15-Foot Low-Speed Wind Tunnel is shown in figure 5 . The CRP/ PTR was located near the middle of the test section axially, approximately 
$2 \mathrm{ft}$ from the test section centerline horizontally, and on the test section centerline vertically. A model support strut was used to mount the CRP/PTR to a rotating platform in the tunnel floor. The rotating platform allowed the CRP/PTR to yaw to simulate angle-of-attack on the model. A photograph of the CRP/PTR at a negative angle-of-attack is shown in figure 6 .

The large forward section of the CRP/PTR, known as the forebody, was designed to represent the faired-over inlet and nacelle sections of the core engine, and has a maximum diameter of $11.94 \mathrm{in.}$ The two rows of counterrotating propeller blades are mounted in the rotor hubs located behind the forebody. The hubs are contoured to provide area-ruling near the blade root section, thus reducing the high flow velocities between the propeller blades. During the portion of the investigation described in this report, the axial distance between the propeller rotors was 5.90 in., defined from the forward rotor pitch-change axis to the aft rotor pitch-change axis. Behind the propelier rotor hubs is the aft section of the CRP/PTR known as the afterbody, designed to simulate the aft section of an engine nacelle and core engine exhaust, and has a minimum diameter of $6.0 \mathrm{in}$. The afterbody section then transitions up to the turbine drive housing, which is $12.0 \mathrm{in}$. in diameter. The model support strut, located in the rear of the CRP/PTR, extends down from the turbine drive housing to the tunnel floor. The length of the CRP/PTR from the front of the forebody to the end of the turbine drive housing is approximately 120 in.

To simulate approximately an aircraft engine support pylon and fuselage, a body-of-revolution and support strut were added to the basic CRP/PTR model configuration. A photograph of the CRP/PTR with the pyion/fuselage simulator installed is shown in figure $7(a)$, and a closeup planform photograph of the forebody and pylon/fuselage arrangement on the CRP/PTR shown in figure $7(b)$. The maximum pylon thickness (at roughly 40 percent chord) varied from 1.31 in. near the forebody to 2.15 in. near the fuselage simulator (the measurements occur at the point of maximum diameter on the forebody and fuselage). The axial distance from the pylon trailing edge to the forward rotor pitch-change axis was 2.66 in. at the propeller hub and 5.25 in. near the propeller tip. The fuselage simulator had a maximum diameter of 25.0 in., approximately 23 in. upstream axially from the forward rotor pitch-change axis. The separation between the forward rotor hub and the fuselage simulator was $10.29 \mathrm{in}$, and $10.97 \mathrm{in}$. between the aft rotor hub and the fuselage simulator.

The CRP/PTR is capable of delivering up to 1350 total shaft horsepower at a maximum rotational speed of $9000 \mathrm{rpm}$ using two two-stage, air-driven, turbines (675 SHP each with $450 \mathrm{psi}, 660^{\circ} \mathrm{R}$ high-pressure air). The power turbines were connected to the propeller rotor hubs via concentric drive shafts. Each turbine is used to supply power to one of the propeller rotor hubs. From an aft-looking-forward position, the inner shaft and forward hub rotate in a counterclockwise direction, while the outer shaft and aft hub rotate in a clockwise direction. A more detailed description of the model propeller test rig is given in reference 8 .

The CRP/PTR instrumentation for determining propeller performance consisted of several types. Loads generated by the propeller rotors during testing were measured using rotating force balances; each rotor hub was attached to the metric side of one of the force balances. The force balance measured the propeller rotor thrust and torque loads using strain-gaged flexure beams. The signals from the force balance were relayed through a telemetry unit to a 
monitoring station. Centrifugal stresses on the flexure beams were measured using strain gages and force balance temperatures were measured using thermocouples attached to the balances. The force balance measurements were corrected using these centrifugal force and temperature measurements. Static pressures were measured on the CRP/PTR forebody and afterbody and in the rotor cavity areas using an electronically scanned pressure (ESP) measurement system. The forebody and afterbody pressure instrumentation consisted of five rows of 13 pressure taps on the forebody and four rows of 12 pressure taps on the afterbody. Pressures on the aircraft pylon and fuselage simulators were not measured. Kulite pressure transducers were used to measure pressures in the cavities between the rotor hubs.

\section{Propeller Designs}

The design philosophy used to generate the counterrotation propeller blades evolved from the philosophy used to design the first advanced high-speed single-rotation blade designs - enhance propeller performance and minimize propeller noise while maintaining a reasonable propeller size. The counterrotation propeller blades incorporated many of the design features necessary to achieve high propulsive efficiency at high flight Mach numbers. These design features included: (1) proper nacelle shaping and hub area-ruling to allow flow diffusion and reduce the blade inboard Mach number, thereby alleviating hub choking; (2) blade sweep, to reduce the effective biade Mach number near the propeller tip and minimize compressibility effects; (3) thin blades, to increase the blade drag-rise Mach number; and (4) large blade chord lengths with large numbers of blades per rotor to obtain a high disk power loading (a higher total power loading than the single-rotation propeller designs) and thereby reduce the propeller diameter. A description of the method used to design the counterrotation unducted fan propeller blades is given in reference 9 .

Table I provides a general summary of the individual model propeller blade design characteristics for the propellers in this report. The "F" signifies forward rotor propeller blades, while the "A" signifies aft rotor blades. The propeller blades were approximately $24 \mathrm{in}$. in diameter, except for the $A 3$ blades. The reduced diameter and wider chord of the A3 propeller blades were chosen to eliminate the interaction of the aft rotor propeller blades with the tip vortex from the forward rotor propeller blades, while maintaining the amount of power absorbed by the aft rotor at the same rotor rotational speed. All the propeller blades were manufactured from composite materials (graphite and epoxy) with titanium spars. Photographs of the propeller blades used in the investigation are shown in figure 8 .

In table II, a summary of the design characteristics of the propeller configurations in this report is given. The investigation was conducted using the $11 / 9$ configuration; 11 blades in the forward rotor and nine blades in the aft rotor. In this way, a high disk power loading could be achieved which would allow a reduction in the propeller tip speed, and therefore the propeller noise, at takeoff conditions. 
Testing Procedure

The low-speed characteristics of two counterrotation propeller configurations with nonuniform inflow were investigated at a Mach number of 0.20 in the NASA Lewis 9- by 15-Foot Low-Speed Wind Tunnel. A summary of the geometries and angles-of-attack tested for each propeller configuration is given in table III.

The propeller configurations were tested over a range of rotational speeds from windmill to the maximum rotational speed allowable; the maximum rotational speed was imposed by the structural limits of the propeller blades, the vibration limits of the CRP/PTR, or, in some cases, the thrust load limits of the rotating force balances. The propeller pitch, or blade, angles (defined at the three-quarter radius point on the propeller blade) were chosen to obtain data near the counterrotation propeller take-off/landing operating point. For each of the propeller configurations, two sets of blade angles were chosen in order to vary the propeller power loading and tip speed for a target operating point. During the investigation, the propeller configurations were typically tested with the propeller rotors at nearly equal, or matched, power and nearly matched rotational speed to obtain the target operating point propeller performance. For CRP/PTR operational considerations, matched rotor rotational speeds meant that the aft rotor rotational speed was set $50 \mathrm{rpm}$ higher than the forward rotor rotational speed at each propeller operating condition.

The effect of a nonuniform flowfield on the propeller performance was determined for each propeller configuration. The flowfield, and hence the inflow velocity to the propeller, was made nonuniform by changing the propeller model angle-of-attack, which meant yawing the CRP/PTR as much as $\pm 16^{\circ}$ (fig. $7(b)$ and table III), or by mounting the aircraft engine support pyion and fuselage simulators on the CRP/PTR ( $f i g .8$ ).

In table IV, the takeoff target operating points, or the desired propeller operating conditions, for the propeller configurations tested are given. As shown in the table, each propeller configuration had more than one set of takeoff operating point blade angles. The higher blade angle settings produced more power (a higher power louding parameter) while operating at lower propeller tip speeds at the target operating point.

\section{Determination of Propeller Net Thrust}

The propeller net thrust is defined as the propulsive force of the propeller operating in the nacelle flowfield and adjusted for the change in the nacelle drag force due to the installed propeller (the propeller/nacelle interaction effect). In other words, the total propeller net thrust is the thrust force measured by the rotating force balances, corrected for: The pressure forces on the force balances with the propeller powered; the drag forces on the propeller rotors without propeller blades; and the difference in the nacelle (forebody and afterbody) pressure drag forces with and without the propeller blades. Since the pressure forces on the aircraft engine support pylon and fuselage simulators were not measured, their effect on the measured propeller thrust force cannot be determined. The effect of the pylon and fuselage simulators on the local nacelle flowfield was determined without the installed propeller when the pressure drag forces on the nacelle were determined. A 
detailed description of the method used in determining the propeller net thrust, including equations and diagrams, is given in reference 5 .

\section{RESULTS AND DISCUSSION}

The basic definitions of propeller net efficiency and advance ratio are,

$$
n_{n e t}=T_{\text {net }}(V / P)
$$

and

$$
J=V /(n D)
$$

In the calculation of the propeller net efficiency and advance ratio, propeller performance values of thrust and torque (which are used to calculate propeller power) are used which are measured with reference to a plane along the axis of the CRP/PTR (and not from a plane along the axis of the tunnel). The flow velocity used is determined from the same CRP/PTR reference plane, and is a component of the freestream velocity. Therefore, when the propeller model is at angle-of-attack, the flow velocity is calculated by multiplying the freestream velocity by the cosine of the angle-of-attack. Using the calculated flow velocity instead of the freestream velocity directly, the propeller performance results as a function of advance ratio are more well behaved, with much less spread in the results, and allows the determination of the propeller performance at angle-of-attack from the $0^{\circ}$ angle-of-attack results. For this report, then, the propeller net efficiency and advance ratio are defined as,

and

$$
n_{c, \text { net }}=T_{\text {net }}\left(V_{0} \cos \alpha / P\right)
$$

$$
J_{C}=V_{0} \cos \alpha /(n D)
$$

The propeller net efficiency in dimensionless form is,

$$
n_{C}, \text { net }=T Q A\left(J_{C} / P Q A\right)
$$

In their dimensionless form, the individual rotor performance parameters are referenced to the individual rotors, while the total propeller performance parameters are referenced to the forward rotor for simplicity.

The propeller performance results are presented for the F7/A3 11/9 and F7/A7 11/9 propeller configurations and show the effect of nonuniform inflow on the propeller performance at Mach number 0.20 . The performance results are presented in two formats. The first format is the overall propeller performance in terms of the basic propeller performance parameters of propeller net efficiency ( $\left.n_{C}, n_{t}\right)$, total power coefficient $\left(P Q A_{T}\right)$, and aft-to-forwardrotor torque ratio as a function of the forward rotor advance ratio $\left(J_{C}, 1\right)$ for different propeller model angles-of-attack with and without the pylon and fuselage simulators. The overall propeller performance is also shown in terms of the propeller net efficiency as a function of the propeller power loading parameter $\left(P Q A_{T} / J_{C, 1}^{3}\right)$. The power loading parameter is a dimensionless measure of the power absorbed by the propeller. In this way, the performance 
of several propeller configurations at different blade angle settings (or the same propeller configuration with different inflow conditions), but having the same target operating point power loading, can be more easily compared to one another and to desired target operating conditions from table IV. In this report, overall propeller performance results are presented as a function of the propeller advance ratio and power loading parameter for only the $F 7 / A 3 \quad 11 / 9$ propeller configuration, since similar trends in the overall propeller performance results were seen for the F7/A7 11/9 propeller configuration.

The second propeller performance presentation format is in terms of the net efficiency, power coefficient, advance ratio, and torque ratio as a function of the propeller model angle-of-attack at constant takeoff target operating point power loading parameters. A constant value of power loading parameter does not imply constant values of power coefficient and advance ratio in the results, even though the power loading parameter is calculated from both, but does imply constant propeller power. Variations in the propeller performance are shown for varying propeller inflow conditions, which were produced by installing the pylon and fuselage simulators and by varying the propeller model angle-of-attack with and without the simulators installed. Performance results are shown for both the F7/A3 11/9 and the F7/A7 11/9 propeller configurations for the test matrix given in table III.

\section{Overall Propeller Performance With and Without} Pylon and Fuselage Simulators

A sample of the overall propeller performance results with and without the pylon and fuselage simulators at different propeller model angles-of-attack are shown for the F7/A3 $11 / 9$ propeller configuration in figures 9 to 11 . The blade angle settings shown (41.1/46.4) represent a takeoff target operating point power loading parameter of 4.365 (table IV).

In figure 9, the F7/A3 11/9 propeller performance with angle-of-attack without the pylon and fuselage simulators is shown. The propeller model angleof-attack was varied between $+16^{\circ}$ (table III). The results show very little change in the propeller net efficiency ( $f i g .9(a)$ ) and relatively small changes in the total power coefficient ( $f i g .9(b)$ ). and aft-to-forward-rotor torque ratio (fig. $9(c)$ ) with changes in the propeller model angle-of-attack, especially near the takeoff target operating point advance ratio of 0.923 (table IV). Somewhat larger varlations in the propeller performance occur at higher advance ratios (lower propeller rotational speeds) and higher model angles-of-attack, where a small decrease in net efficiency and a slight increase in the total power coefficient is shown in the results with angle-of-attack. The results show a small decrease in the torque ratio at the lower advance ratios at the highest angles-of-attack. The net efficiency results as a function of the power loading parameter ( $f i g . g(d)$ ) indicate a decrease in performance with angle-of-attack at the lower power loadings. As can be seen in the figure, the performance results collapse to a single curve with angle-of-attack by using the velocity component along the axis of the CRP/PTR in the calculation of the net efficiency and advance ratio.

The performance results with only the pylon simulator installed with angle-of-attack for the F7/A3 11/9 propeller configuration are shown in figure 10. For this configuration, vibration limits on the CRP/PTR limited the 
variation in the propeller model angle-of-attack to between $+12^{\circ}$ (table III). The performance results indicate no change in the propeller net efficiency (fig. $10(a)$ ) with angle-of-attack due to the pylon simulator, except for a small increase in net efficiency at the highest angles-of-attack. However, the total power coefficient and torque ratio results (figs. $10(b)$ and (c)) show much larger variations with the pylon simulator installed with angle-of-attack than the performance variations seen without the pylon simulator installed. The total power coefficient results show large increases due to the pylon simulator at positive angles-of-attack and smaller decreases at negative angles-ofattack. In terms of the torque ratio, the results show large increases due to the pylon simulator at negative angles-of-attack and somewhat smaller decreases at positive angles-of-attack.

Clearly, the propeller performance is effected by the addition of the pylon simulator, which produces nonuniformities in the propeller flowfield at angle-of-attack in the form of preswirl on the side of the propeller near the pylon simulator and, possibly, in the form of separated flow over the pylon at the larger angles-of-attack. The performance results also indicate that the changes in the propeller total power and in the torque split between the propeller rotors were not symmetric with angle-of-attack.

A velocity vector diagram of a propeller blade section on the forward rotor (with the rotor rotation in a counterclockwise direction from an aftlooking-forward, or upstream, perspective) shows that with a variation in the propeller model angle-of-attack, the blade section experiences a constantly varying local angle-of-attack during each propeller revolution. The propeller blade section experiences the largest variations in the local angle-of-attack at locations in the propeller plane perpendicular to the model pitching plane (in this case, the CRP/PTR yaws to angle-of-attack (fig. 6), and the largest changes in the local blade section angle-of-attack occurring at the top and the bottom of the propeller plane of rotation). Since the rotational direction of the aft rotor is opposite that of the forward rotor, the aft rotor experiences changes in local angle-of-attack opposite to the forward rotor with changes in the model angle-of-attack. The change in the local blade section angle-ofattack is also equal and opposite at opposite locations on the propeller plane. Therefore, without further disturbances to the flowfield, the steady state propeller performance does not change with propeller model angle-of-attack.

With the addition of the pylon preswirl to the flowfield on one side of the propeller, the flowfield undergoes an asymmetric disturbance. On the side of the propelier without the pylon simulator, the change in the local blade section angle-of-attack is due to the model angle-of-attack. On the side of the propeller with the pylon simulator, the change in the local blade section angle-of-attack due to the pylon preswirl at model angles-of-attack is not as large, or is negated altogether. As a result, when averaged over the entire propeller plane, the forward rotor experiences an increase in the local angleof-attack at positive model angles-of-attack and a decrease in the local angleof-attack at negative model angles-of-attack. At the same time, the aft rotor experiences just the opposite effect at model angle-of-attack due to the pylon preswirl in terms of the local angle-of-attack. Therefore, with the pylon preswirl, the forward rotor power increases as the propeller model angle-of-attack increases, while the aft rotor power increases as the model angle-of-attack

decreases. This explains the changes in the total power coefficient results 
(fig. $10(b)$ ) and the large changes in the torque ratio results (fig. 10(c)) at model angle-of-attack.

The F7/A3 propeller performance results also indicate an asymmetry in the variations in the total power coefficient and torque ratio between positive and negative angles-of-attack, implying larger changes in the forward rotor power than the aft rotor power at angle-of-attack. One reason may be that the aft rotor experiences a smaller variation in the inflow conditions (smaller variation in the local blade section angle-of-attack) than the forward rotor at model angle-of-attack, because the forward rotor may be turning the flow away from the freestream direction and more in a direction along the axis of the CRP/PTR. Another reason may be that the forward rotor blades are more sensitive to changes in the model angle-of-attack than the smaller diameter A3 aft rotor blades, meaning that the difference in power on the aft rotor with angleof-attack is not as large as the difference in power on the forward rotor with angle-of-attack. In other words, the full-size F7 forward rotor blades may not be absorbing the same amount of power at positive angles-of-attack than the smaller diameter $A 3$ at negative angles-of-attack, and vice-versa. The smaller diameter $A 3$ blades may possibly be stiffer, due to the smaller diameter and wider blade chord than, the F7 forward rotor blades, and therefore the $A 3$ blades may be not be deflecting as much during propeller operation.

The F7/A3 11/9 net efficiency results as a function of the power loading parameter ( $f i g .10(d)$ ) also show small differences due to the pylon simulator with model angle-of-attack, except in the $+12^{\circ}$ case, where the net efficiency is noticeably higher at all values of power loading parameter. The reason for this increase is not clear, however a large increase in the total power coefficient (fig. $10(b)$ ) can also be seen at the same model angle-of-attack. These increases in the performance at the higher model angles-of-attack may be due to some interaction of the propeller model with the test section wall and wall recirculation slots (figs. 5 to 7). Interestingly, the large differences shown in the propeller rotor power and the torque ratio with angle-of-attack have no appreciable effect on the propeller net efficiency.

The performance results of the F7/A3 11/9 propeller configuration at angle-of-attack with both the pylon and fuselage simulators installed are shown in figure 11. The trends in the propeller performance with both the pylon and fuselage simulators installed at angle-of-attack are very similar to the performance trends shown with only the pylon simulator installed (fig. 10). The performance results indicate almost no change in propeller net efficiency (fig. $11(2)$ ) due to the simulators with model angle-of-attack except at $+12^{\circ}$, where a small increase in net efficiency is shown at all advance ratios. In addition, the net efficiency results with both simulators installed at all angles-of-attack are approximately 0.8 percent higher than the net efficiency results with only the pylon simulator installed (fig. 10(a)). The total power coefficient (fig. $11(b)$ ) results show the large increases due to the simulators at positive angles-of-attack and the smaller decreases at negative angles-ofattack, similar to the total power coefficient results shown in figure $10(b)$. The total power coefficient results with both simulators installed at all angles-of-attack are approximately 0.8 percent lower than the results shown in figure $10(b)$ with only the pylon simulator installed. The propeller torque ratio results ( $f i g . \quad l l(c)$ ) also indicate large increases due to the simulators at negative model angles-of-attack and smaller decreases at positive angles-of- 
attack. The torque ratio results with both simulators installed also show larger differences with model angle-of-attack than the torque ratio results with only the pylon simulator installed shown in figure 10(c). The net efficiency results as a function of the power loading parameter (fig. 11(d)) show almost no change due to the simulators at model angle-of-attack except at $+12^{\circ}$, where the net efficiency increases approximately one percent at all advance ratios. In addition, the net efficiency results with both simulators installed are approximately 0.6 percent higher than the net efficiency results with only the pylon simulator installed in figure $10(d)$.

The F7/A3 11/9 propeller performance results shown in figures 9 to 11 indicate that nonuniformities produced in the propeller flowfield with the propeller model at angle-of-attack had a small effect on the propeller performance without the aircraft pylon and fuselage simulators installed (fig. 9). However, by installing the pylon simulator on the CRP/PTR, pronounced effects on the propeller total power coefficient and torque ratio were shown (figs. 10(b) and $(c)$ ), due to the large disturbances produced in the propeller flowfield by the pylon preswirl with the propeller model at angle-of-attack. Installing both the pylon and fuselage simulators caused a small increase in propeller performance at all angles-of-attack ( $f i g .11$ ), and even larger changes in the total power coefficient and torque ratio (figs. $11(\mathrm{~b})$ and (c)) with angle-ofattack than with only the pylon simulator. The fuselage simulator produced even further disturbances in the propeller flowfield, possibly by increasing the local blockage near the propellers or by producing a region of separation in the flowfield with the model at angle-of-attack. Interestingly, the large variations in the propeller total power coefficient and torque ratio with angle-of-attack with the pylon or the pylon and fuselage simulators installed (figs, $10(b)$ and $(c)$ and $11(b)$ and $(c)$ ) produced relatively small changes in the propeller net efficiency (figs. 10(a) and $11(a)$ ). This result indicates that the dominant loss mechanism in the propeller performance, which causes a lower level of net efficiency performance at low-speed conditions, is not the unrecovered swirl produced by the forward operating propeller (or, in this case, especially in the tip region due to the smaller diameter A3 blades).

Effect of Power Loading on Propeller Performance Wi thout Pylon and Fuselage Simulators

In figures 12 and 13 , performance results for the $F 7 / A 311 / 9$ and $F 7 / A 7$ $11 / 9$ propeller configurations as a function of angle-of-attack at constant takeoff target power loading parameters are presented. The results are presented at constant takeoff target power loading parameters of 3.829 and 4.365 , which represents a change in power of approximately 14 percent. The power loading parameters correspond to propeller tip speeds of 815 and 760 fps, respectively, at the takeoff target operating point (table IV). As mentioned earlier, a constant power loading parameter indicates that the propeller power, and not the total power coefficient and the advance ratio, was constant.

In figure 12 , the results for the F7/A3 11/9 configuration without the pylon and fuselage simulators installed are shown. The propeller model angleof-attack was varied between $+16^{\circ}$ (table III). The results show that the propeller net efficiency ( $f i g .1 \overline{2}(a)$ ) was fairly insensitive to changes in the propeller model angle-of-attack at either target power loading parameter. The results also clearly show the decrease in net efficiency at the higher power 
loading parameter due to the increase in the propeller power, approximately -3.4 percent at $0^{\circ}$ angle-of-attack and -3.8 percent at $-16^{\circ}$ angle-of-attack. The propeller total power coefficient ( $f i g .12(b)$ ) and advance ratio

(fig. 12(c)) results show very little change with angle-of-attack at the higher power loading parameter, but a small increase at the lower power loading parameter with angle-of-attack $(+1.83$ percent in total power coefficient and +0.57 percent in advance ratio from $0^{\circ}$ to $-16^{\circ}$ ). The increase in the total power coefficient between the higher and the lower power loading parameter is +39.17 percent at $0^{\circ}$ angle-of-attack and +37.45 percent at $-16^{\circ}$ angle-ofattack. The decrease in the torque ratio results with angle-of-attack (fig. $12(d)$ ) can be seen at both power loading parameters, with a slightly larger decrease at the lower power loading parameter $\left(-2.32\right.$ percent from $0^{\circ}$ to $\left.-16^{\circ}\right)$. The difference in the torque ratio results at $0^{\circ}$ angle-of-attack could be due to slightly mismatched rotor speeds or blade angle settings which are off slightly. The design torque ratio is 1.0 at all propeller target operating points.

The performance of the F7/A7 11/9 propeller configuration at angle-ofattack without the pylon and fuselage simulators at constant target power loading parameters of 3.829 and 4.365 is shown in figure 13. In this case, the model angle-of-attack was varied between $+8^{\circ}$ and $-16^{\circ}$ at the lower power loading parameter, and between $0^{\circ}$ and $-16^{\circ}$ at the higher power loading parameter. Limited test time resulted in the reduced test matrix for this configuration. The performance results are very similar to the F7/A7 11/9 configuration performance results shown in figure 12. The performance results indicate that the propeller net efficiency is fairly insensitive to changes in the model angleof-attack (fig. 13(a)). Here, the decrease in net efficiency due to the increase in the power loading parameter is -3.10 percent at $0^{\circ}$ angle-of-attack and -3.25 percent at $-16^{\circ}$ angle-of-attack. The total power coefficient and advance ratio results (fig. $13(b)$ and (c)) show very little change with angleof-attack at the higher power loading parameter and a slightly decreasing trend with angle-of-attack at the lower power loading parameter $(-1.34$ percent in total power and -0.46 percent in advance ratio for a change of $0^{\circ}$ to $-16^{\circ}$ ). The increase in the total power coefficient due to the power loading parameter is +38.37 percent at $0^{\circ}$ angle-of-attack and +36.90 percent at $-16^{\circ}$ angle-ofattack. The torque ratio results (fig. 13(d)) generally show a decrease with angle-of-attack at both power loading parameters, with a slightly larger decrease at the lower power loading parameter $(-1.99$ percent for a change of $0^{\circ}$ to $\left.-16^{\circ}\right)$.

A comparison of the propeller performance between the $F 7 / A 311 / 9$ and the F7/A7 11/9 propeller configurations shows that the $F 7 / A 7$ configuration has a higher net efficiency ( $f i g .13(a)$ ) than the F7/A3 configuration ( $\mathrm{fig} .12(2)$ ) at both power loading parameters. At the lower power loading parameter, the results show the $F 7 / A 7$ net efficiency is +3.1 percent higher than the $F 7 / A 3$ net efficiency at both $0^{\circ}$ and $-16^{\circ}$ angle-of-attack. At the higher power loading parameter, the F7/A7 net efficiency is +3.3 percent higher at $0^{\circ}$ angle-ofattack and +3.6 percent higher at $-16^{\circ}$ angle-of-attack. Comparing the total power coefficient results for the $F 7 / A 3$ and $F 7 / A 7$ configurations (figs. 12(b) and $13(b))$, the $F 7 / A 7$ configuration results show a lower total power coefficient than the F7/A3 configuration at both power loading parameters. At the lower power loading parameter, the F7/A7 total power coefficient is -2.26 percent lower than the $F 7 / A 3$ total power loading at $0^{\circ}$ angle-of-attack and -2.73 percent lower at $-16^{\circ}$ angle-of-attack. At the higher power loading parameter, 
the F7/A7 total power coefficient is -2.82 percent lower at $0^{\circ}$ angle-of-attack and -3.12 percent lower at $-16^{\circ}$ angle-of-attack. Part of the reason for these differences in the power coefficient between the propeller configurations is that the propeller blade angle settings necessary to achieve the takeoff target operating point power coefficients (table IV) were off slightly for both propeller configurations. As a result, the F7/A3 configuration produced more power than the F7/A7 configuration (higher total power coefficient) at each power loading parameter. The higher F7/A7 configuration net efficiency verses the $F 7 / A 3$ configuration is due in part to the slightly lower F7/A7 total power coefficient results, but the results also indicate that the low-speed performance of the F7/A7 11/9 configuration is slightly better with the full-size A7 aft rotor blades than the F7/A3 configuration with the smaller diameter A3 aft rotor blades.

\section{Take-Off Target Operating Point Propeller Performance} With and Without Pylon and Fuselage Simulators

In figures 14 and 15 , the performance of the $F 7 / A 311 / 9$ and $F 7 / A 711 / 9$ propeller configurations as a function of the propeller model angle-of-attack at a constant target power loading parameter of 4.365 (table IV) is shown. The results are presented to show the effect of the pylon and fuselage simulators on the propeller performance with angle-of-attack.

In figure 14, the $F 7 / A 311 / 9$ configuration performance is shown, including the individual net efficiency and power coefficient results for the forward and aft rotors. The model angle-of-attack was varied between $+16^{\circ}$ without the simulators installed, and between $+12^{\circ}$ with only the pylon and with the pylon and fuselage simulators installed (table III). The performance results presented were obtained from the F7/A3 configuration results shown in figures 9 to 11 for a constant takeoff target power loading parameter of 4.365 at all model anglesof-attack.

The F7/A3 11/9 configuration net efficiency results are shown in figures $14(a)$ to $(c)$. The propeller net efficiency results (fig. 14(a)) indicate relatively small changes occur at angle-of-attack with or without the pylon and fuselage simulators installed. Without the pylon and fuselage simulators installed, a small decrease in the net efficiency is shown with angle-of-attack $\left(-0.35\right.$ percent for a change of $0^{\circ}$ to $\left.+16^{\circ}\right)$, while a slight increase is shown with angle-of-attack with the simulators installed, especially at positive angles-of-attack $\left(+0.85\right.$ percent for a change of $0^{\circ}$ to $+12^{\circ}$ with both simulators installed). The largest difference in the net efficiency due to the installation of the pylon and fuselage simulators can be seen at $+12^{\circ}$ angle-of-attack (an increase of +1.2 percent).

The forward rotor and aft rotor net efficiency results are shown in figures $14(b)$ and (c). The forward rotor results (fig. 14(b)) show a slight decrease in the net efficiency when the simulators are installed $(-0.5$ percent at $0^{\circ}$ angle-of-attack when both simulators are installed). At angle-of-attack, the forward rotor results show very little change in the net efficiency due to the installation of the simulators, except at $+12^{\circ}$ where a small increase is shown when each simulator is installed $\left(+0.65\right.$ percent for a change of $0^{\circ}$ to $+12^{\circ}$ with both simulators installed). At the higher angles-of-attack, the differences in the forward rotor net efficiency due to the installation of the 
simulators were very small. The aft rotor net efficiency results (fig. 14(c)) indicate somewhat larger changes occur when the simulators are installed and with angle-of-attack. The aft rotor results show an increase in the net efficiency with the simulators installed $\left(+0.8\right.$ percent at $0^{\circ}$ angle-of-attack when both simulators installed). With angle-of-attack, the aft net efficiency decreases slightly without the simulators installed $(-0.8$ percent for a change of $0^{\circ}$ to $-16^{\circ}$ ) and tends to increase when each simulator is installed, especially with negative angles-of-attack $\left(+1.4\right.$ percent for a change of $0^{\circ}$ to $-12^{\circ}$ with the pylon simulator installed). The largest difference in aft rotor net efficiency due to the installation of the simulators can be seen at $-12^{\circ}$ angleof-attack (an increase of +1.8 percent when both simulators are installed).

The net efficiency results show that the aft rotor is somewhat more sensitive to changes in the propeller flowfield than the forward rotor, since the performance trends with angle-of-attack show much larger variations in net efficiency for the aft rotor than for the forward rotor. However, the forward rotor and aft rotor net efficiencies cannot be compared directly. The reason is that the pressure force corrections used to obtain the propeller net thrust (as discussed earlier in the section on determination of propeller net thrust and in ref. 5) can only be directly applied to the total propeller thrust force measurements. The individual rotor values of net thrust were determined by applying the internal cavity pressure force corrections for each rotor and onehalf of the total nacelle pressure force corrections to the thrust force measured by each rotor force balance. The internal pressure force corrections between the rotors were not always reliable, and when applied to individual rotor thrust force measurements, could cause exaggerated values of the individual rotor net thrust which is used to calculate the rotor net efficiency. When the pressure force corrections are applied to the total propeller thrust force measurement, the internal pressure force corrections between the rotors are cancelled. As a result, only trends in the net efficiency for each rotor with angle-of-attack with and without the simulators installed were considered, and the individual rotor net efficiencies should not be directly compared.

The F7/A3 $11 / 9$ configuration power coefficient results are shown in figures $14(d)$ to $(f)$. The propeller total power coefficient results (fig. 14(d)) indicate a slight decrease when both the pylon and fuselage simulators are installed $\left(-0.71\right.$ percent at $0^{\circ}$ angle-of-attack). With the model at angle-ofattack, the results show essentially no change in the total power coefficient without the simulators installed. Due the installation of the simulators, the results indicate an increase in the total power coefficient with positive angle-of-attack $\left(+2.73\right.$ percent for a change of $0^{\circ}$ to $+12^{\circ}$ with both simulators installed) and generally a small decrease in the total power coefficient with negative angle-of-attack $\left(-1.23\right.$ percent for a change of $0^{\circ}$ to $-8^{\circ}$ with both simulators installed). The total power coefficient results show the largest change with angle-of-attack due to the installation of the simulators was an increase of +2.60 percent at $+12^{\circ}$ angle-of-attack with the pylon simulator installed and a decrease of -2.25 percent at $-12^{\circ}$ angle-of-attack with both simulators installed.

In figures $14(e)$ and ( $f$ ), the forward rotor and aft rotor individual power coefficient results are shown. The forward rotor power coefficient results (fig. 14(e)) indicate essentially no change occurs when the simulators are installed. The forward power coefficient results show very small increases without the simulators installed with angle-of-attack $<+1.38$ percent for a 
change of $0^{\circ}$ to $-16^{\circ}$ ). However, large increases in the forward power coefficient can be seen due to the installation of the simulators with positive angle-of-attack $\left(+19.39\right.$ percent for a change of $0^{\circ}$ to $\left.+12^{\circ}\right)$ and large decreases due to the simulators can be seen with negative angle-of-attack $(-19.05$ percent for a change of $0^{\circ}$ to $-12^{\circ}$ ). The forward power coefficient results show that the largest changes with angle-of-attack due to the installation of the simulators was an increase of +18.64 percent at $+12^{\circ}$ angle-of-attack and a decrease of -20.06 percent at $-12^{\circ}$ angle-of-attack with both the pylon and fuselage simulators installed.

The aft rotor power coefficient results are shown in figure 14(f), and have been nondimensionalized by the forward rotor geometry for consistency, since very large values of power coefficient would be calculated using the aft rotor geometry. The aft rotor results indicate trends in the power coefficient which are opposite the trends shown in the forward rotor results (fig. 14(e)). The aft results show a slight increase in the power coefficient when the pylon simulator is installed ( +0.41 percent at $0^{\circ}$ angle-of-attack) and a slight decrease when both the pylon and fuselage simulators are installed $(-0.98$ percent at $0^{\circ}$ angle-of-attack). The aft results show a very small decrease in power coefficient without the pylon and fuselage simulators installed with angle-of-attack $\left(-0.87\right.$ percent for a change of $0^{\circ}$ to $\left.+16^{\circ}\right)$. However, the aft results show large decreases in the aft power coefficient due to the installation of the simulators with positive angle-of-attack $(-14.27$ percent for a change of $0^{\circ}$ to $+12^{\circ}$ with both simulators installed) and large increases due to the simulators with negative angle-of-attack $(+16.67$ percent for a change of $0^{\circ}$ to $-12^{\circ}$ with both simulators installed). The aft rotor power coefficient results show that the largest change with angle-of-attack due to the simulators was a decrease of -14.60 percent at $+12^{\circ}$ angle-of-attack and an increase of +15.46 percent at $-12^{\circ}$ angle-of-attack with both the pylon and fuselage simulators installed. Since the variations in the power coefficient results are larger on the forward rotor (fig. 14(e)) than the aft rotor, the forward rotor has a larger influence on the total power coefficient results (fig. 14(d)) at angle-of-attack.

The F7/A3 11/9 configuration advance ratio results are shown in figure $14(\mathrm{~g})$. The propeller advance ratio results indicate the same trends as the total power coefficient results ( $f i g .14(d)$ ), since the power loading parameter is constant. The results show no change in the advance ratio due to the installation of the pylon simulator, and a slight decrease due to the installation of the pylon and fuselage simulators $\left(-0.32\right.$ percent at $0^{\circ}$ angle-ofattack). The aft results also indicate essentially no change in the advance ratio without the pylon and fuselage simulators installed with angle-of-attack. With the installation of the simulators, a small increase in the advance ratio results is shown with positive angle-of-attack $(+0.97$ percent for a change of $0^{\circ}$ to $+12^{\circ}$ with both simulators installed) and a small decrease is shown with negative angle-of-attack $\left(-0.32\right.$ percent for a change of $0^{\circ}$ to $-12^{\circ}$ with both simulators installed). The largest change in the advance ratio results with angle-of-attack due to the installation of the simulators was a +0.97 percent increase at $+12^{\circ}$ angle-of-attack (with only the pylon simulator installed) and a -0.75 percent decrease at $-12^{\circ}$ angle-of-attack (with both simulators installed).

The aft-to-forward-rotor torque ratio results for the $F 7 / A 311 / 9$ configuration are shown in figure $14(\mathrm{~h})$, and indicate large variations in the torque 
split between the rotors due to the installation of the pylon and fuselage simulators with angle-of-attack. The torque ratio results give an indication of the power split between the rotors, since the rotor power is directly related to the rotor torque. The results show essentially no change in the torque ratio when the pylon simulator is installed and a slight decrease in the torque ratio when both the simulators are installed $\left(-1.00\right.$ percent at $0^{\circ}$ angle-ofattack). With angle-of-attack, very small decreases in the torque ratio are shown in the results without the simulators installed $(-1.59$ percent for a change of $0^{\circ}$ to $-16^{\circ}$ angle-of-attack), and large changes are apparent due to the installation of the pylon and fuselage simulators. The torque ratio results are consistent with the power coefficient results shown in figures $14(e)$ and ( $f$ ), and indicate the decrease in the torque ratio due to the simulators with positive angle-of-attack ( -27.87 percent for a change of $0^{\circ}$ to $+12^{\circ}$ with both simulators installed) and the increase at negative angle-ofattack $\left(+44.67\right.$ percent for a change of $0^{\circ}$ to $-12^{\circ}$ with both simulators installed). The largest difference in the torque ratio with angle-of-attack due to the installation of the simulators was a decrease of -28.06 percent at $+12^{\circ}$ angle-of-attack and an increase of +44.42 percent at $-12^{\circ}$ angle-of-attack. Interestingly, the torque ratio results show the asymmetry between positive and negative angles-of-attack with the simulators installed, indicating that the variations in the aft rotor performance with the simulators installed at angleof-attack are not the same as the variations in the forward rotor performance, as described in figure 10.

The net efficiency, power coefficient and torque ratio results (figs. 14(a) to ( $f$ ) and $14(h)$ ) seem to verify the earlier discussions (figs. 10 and 11 ) on the effect of the pylon and fuselage simulators on the propeller performance. The changes to the propeller flowfield produced by the pylon preswirl and by the flow around the fuselage simulator cause variations in the propeller performance, which are shown by large differences in the propeller power coefficient (figs. $14(d)$ to (f)) and torque ratio (fig. 14(h)) with angle-of-attack, especially in the individual rotor performance. In general, the differences in the propeller performance were larger with both the pylon and fuselage simulators installed than without either the simulator installed or with just the pylon simulator installed at angle-of-attack. The power coefficient and torque ratio results also show the higher sensitivity of the forward rotor performance at angle-of-attack than the aft rotor (figs. $14(d)$ to (f) and $14(h)$ ), as discussed earlier for figure 10 .

The propeller performance for the F7/A7 11/9 propeller configuration at a constant takeoff power loading parameter of 4.365 (table IV) is shown in figure 15. The performance results are presented at angles-of-attack between $-16^{\circ}$ and $0^{\circ}$ without the pylon and fuselage simulators installed and at angles-ofattack between $+12^{\circ}$ with both the pylon and fuselage simulators installed. The $F 7 / A 7$ performance results follow trends with and without the simulators installed at angle-of-attack very similar to the previous results shown for the F7/A3 configuration (fig. 14).

The F7/A7 11/9 propeller net efficiency results are shown in figure $15(a)$. The results show essentially no change in net efficiency due to angle-of-attack without the simulators installed. When the simulators are installed, the results indicate a decrease in the net efficiency $\left(-1.2\right.$ percent at $0^{\circ}$ angle-ofattack). This is a much larger difference than shown for the F7/A3 configuration in figure $14(a)$. A small increase in net efficiency due to the 
installation of the simulators is shown with angle-of-attack, especially at negative angles-of-attack $\left(+0.8\right.$ for a change of $0^{\circ}$ to $\left.-16^{\circ}\right)$. The largest difference in the net efficiency with angle-of-attack due to the installation of the simulators is at $0^{\circ}$ angle-of-attack, which is different than the F7/A3 net efficiency results ( $f i g .14(a)$ ).

The F7/A7 total power coefficient and advance ratio results are shown in figures $15(b)$ and $(c)$. The results indicate a slight decrease in the power coefficient $\left(-0.59\right.$ percent at $0^{\circ}$ angle-of-attack) and advance ratio $(-0.22$ percent at $0^{\circ}$ angle-of-attack) when the simulators are installed. Essentially no change in the power coefficient and the advance ratio is shown due to angle-ofattack without the simulators installed. The results due to the installation of the simulators show a small increase in both the power coefficient and advance ratio with positive angle-of-attack $(+2.36$ percent in power coefficient and +0.76 percent in advance ratio for a change of $0^{\circ}$ to $+12^{\circ}$ ) and a slight decrease in both the total power coefficient and advance ratio with negative angle-of-attack $(-1.12$ percent in power coefficient and -0.33 percent in advance ratio for a change of $0^{\circ}$ to $-8^{\circ}$ ), except at $-12^{\circ}$ angle-of-attack where a slight increase in the results is shown. The largest differences in the power coefficient and advance ratio results with angle-of-attack due to the installation of the simulators are shown at $-8^{\circ}$ angle-of-attack, with a decrease of -1.99 percent in power coefficient and -0.65 percent in advance ratio.

The $F 7 / A 7$ 11/9 aft-to-forward-rotor torque ratio results are shown in figure $15(d)$. A slight increase in the torque ratio is shown when the simulators are installed $\left(+2.42\right.$ percent at $0^{\circ}$ angle-of-attack). A slight decrease in the torque ratio is shown with angle-of-attack without the simulators installed $\left(-1.71\right.$ percent for a change of $0^{\circ}$ to $\left.-16^{\circ}\right)$. At angle-of-attack, the results indicate the large changes in torque ratio due to the simulators, with a decrease shown at positive angles-of-attack ( -30.68 percent for a change of $0^{\circ}$ to $\left.+12^{\circ}\right)$ and an increase shown at negative angles-of-attack $(+47.59$ percent for a change of $0^{\circ}$ to $-12^{\circ}$ ). The largest difference in the torque ratio due to the installation of the simulators was an increase of +52.67 percent at $-12^{\circ}$ angle-of-attack.

The trends in the performance shown for the F7/A7 configuration in figure 15 are very similar to the performance trends shown for the $F 7 / A 3$ in figure 14. Without the pylon and fuselage simulators installed, the propeller performance trends due to angle-of-attack for the two propeller configurations are nearly the same, showing very small or no changes in the performance parameters with angle-of-attack, especially the propeller net efficiency. With the pylon and fuselage simulators installed, the performance trends for both propeller configurations show small differences in net efficiency, but large variations in the power coefficient and torque ratio, at angle-of-attack. In addition, the results show that the effect of the pylon and fuselage simulators on the propeller performance at angle-of attack is somewhat larger for the F7/A7 configurations than for the F7/A3 configuration in terms of net efficiency and torque ratio, while the effect of the simulators at angle-of-attack is slightly smaller for the performance of F7/A7 than for F7/A3 in terms of total power coefficient and advance ratio.

As discussed earlier, the net efficiency of the F7/A7 11/9 configuration (fig. 13(a)) was higher than the F7/A3 $11 / 9$ configuration (fig. 12(a)) at all 
angles-of-attack without the simulators installed. The same trend in the performance is shown with the simulators installed, with the F7/A7 configuration (fig. 15(a)) showing a higher net efficiency than the $F 7 / A 3$ configuration (fig. 14(a)) at all angles-of-attack $\left(+2.0\right.$ percent higher at $0^{\circ}$ angle-of-attack and +2.9 percent at $-12^{\circ}$ angle-of-attack with both simulators installed). The results also show that the F7/A7 total power coefficient (fig. 15(b)) is lower with the simulators installed than the F7/A3 total power coefficient (fig. $14(d)$ ) at all angles-of-attack ( -2.77 percent at $0^{\circ}$ angle-of-attack and -3.14 percent at $+12^{\circ}$ angle-of-attack with both simulators installed). The effect of the smaller diameter $A 3$ aft rotor blades on the propeller performance with the pylon and fuselage simulators installed can be seen by the smaller variations in the F7/A3 power coefficient (figs. 14(d) to ( $f$ )) and torque ratio (fig. $14(h)$ ) results with angle-of-attack than the variations in the F7/A7 power coefficient and torque ratio results ( $f i g s .15(b)$ and (d)), as well as in the asymmetric variations with angle-of-attack in the F7/A3 forward and aft rotor results (figs. $14(e)$ and $(f)$ ). As discussed earlier with figure 10, the smaller diameter and possibly stiffer $A 3$ blades has an effect on the amount of power absorbed compared to the full-size A7 aft rotor blades on the F7/A7 configuration, hence the variations in the $F 7 / A 3$ power coefficient and torque ratio performance due to the simulators at angle-of-attack are not as large.

\section{SUMMARY OF RESULTS}

The low-speed aerodynamic performance characteristics of two advanced counterrotation pusher-propeller configurations, the F7/A3 and the F7/A7 with blade numbers of 11/9 on the forward and aft rotors and designed for a cruise Mach number of 0.72 , were investigated in the NASA Lewis 9- by 15-Foot LowSpeed Wind Tunnel in support of the Advanced Turboprop Project. The investigation was conducted at a Mach number of 0.20 , which is representative of an aircraft takeoffllanding flight regime. The propeller performance characteristics were determined for the two propeller configurations over several blade angle settings and a range of rotational speeds while operating with nonuniform inflow conditions to the propeller. The nonuniform inflow conditions were produced by varying the propeller model angle-of-attack by as much as $\pm 16^{\circ}$ and by installing on the counterrotation propeller test rig simulators representative of an aircraft engine support pylon and fuselage.

The results obtained from the investigation indicate the following:

1. The propeller net efficiencies for both propeller configurations were reasonable at all propeller takeoff target operating conditions. In addition the F7/A7 configuration had a higher net efficiency than the F7/A3 configuration at all operating conditions.

2. The propeller net efficiency for both propeller configurations was fairly insensitive to large angles-of-attack at the takeoff target operating conditions when the component of the freestream velocity along the propeller axis was used to calculate the propeller net efficiency and advance ratio.

3. The propeller power coefficient and aft-to-forward-rotor torque ratio variation with angle-of-attack for both propeller configurations was small without the pylon and fuselage simulators installed. A slight change in the power coefficient and torque ratio performance was seen when the pyion and 
fuselage simulators were installed at $0^{\circ}$ angle-of-attack. At nonzero anglesof-attack, larger differences were seen in the power coefficient (as much as 20 percent on the forward rotor for F7/A3) and torque ratio (as much as 53 percent) for both propeller configurations due to the pylon preswirl and the flow in the area of the fuselage at angle-of-attack. The pylon simulator had a much larger effect on the power coefficient and torque ratio than the fuselage simulator for both propeller configurations.

4. For both propeller configurations, the variations in the power coefficient and torque ratio with the simulators installed were not symmetric at positive and negative angles-of-attack. With the simulators installed, the forward rotor power coefficient was more sensitive to changes in the model angle-of-attack than the aft rotor. This may be a result of the forward rotor turning the flow in a direction more along the axis of the propeller test rig, reducing the angle-of-attack variation seen by the aft rotor. For the F7/A3 configuration, smaller blade deflections on the shorter and stiffer $A 3$ blades may also reduce the angle-of-attack variation seen by the aft rotor.

5. The large changes in aft-to-forward-rotor torque ratio accompanied by small changes in propeller net efficiency indicate that the unrecovered propeller swirl losses are not the dominant propeller performance loss mechanism at low-speed operating conditions.

\section{REFERENCES}

1. Groeneweg, J.F., and Bober, L.J., "NASA Advanced Propeller Research," NASA TM-101361, 1988.

2. Stefko, G.L., Rose, G.E., and Podboy, G.G., "Wind Tunnel Performance Results of an Aeroelastically Scaled 2/9 Model of the PTA Flight Test Prop-Fan," NASA TM-89917, 1987.

3. Stefko, G.L. and Jeracki, R.J., "Wind-Tunnel Results of Advanced High-Speed Propellers at Take-Off, Climb, and Landing Mach Numbers," NASA TM-87030, 1985.

4. Jeracki, R.J. and Rose, G.E., "Measurements of High-Speed, Highly-Loaded Counterrotation Propeller Performance: Effects of Mach Number and Loading (F7/A7)", NASA TM-101429, 1989.

5. Hughes, C.E. and Gazzaniga, J.A., "Summary of Low-Speed Wind Tunne 1 Results of Several High-Speed Counterrotation Propeller Configurations," NASA TM-100945, 1988.

6. Whitlow, J.B., Jr. and Sievers, G.K., "Fuel Savings Potential of the NASA Advanced Turboprop Program," NASA TM-X-83736, 1984.

7. Hughes, C.E., "Flowfield Measurements in the NASA Lewis Research Center 9by 15-Foot Low-Speed Wind Tunne1," NASA TM-100883, 1989.

8. Delaney, B.R., Balan, C., West, H., Humenik, F.M., and Craig, G., "A Model Propulsion Simulator for Evaluating Counter Rotating Blade

Characteristics," SAE Paper 861715, Oct. 1986. 
9. Smith, L.H., Jr., "Unducted Fan Aerodynamic Design," ASME Paper 87-GT-233, May, 1987.

TABLE I. - COUNTERROTATION PROPELLER MODEL BLADE DESIGN CHARACTERISTICS

[ Value in parenthesis indicates A3 Activity Factor based on the A7 propeller model blade diameter ]

\begin{tabular}{|c|c|c|c|}
\hline Propeller model blade & F7 & A3 & A7 \\
\hline Design Mach number & 0.72 & 0.72 & 0.72 \\
Activity Factor per blade & 150 & $240(125)$ & 150 \\
Tip sweep angle, deg & 34 & 22 & 31 \\
Reference diameter, in & 24.64 & 20.98 & 23.94 \\
$\begin{array}{c}\text { Ratio of hub diameter to } \\
\text { propeller diameter }\end{array}$ & .424 & .474 & .415 \\
\hline
\end{tabular}

TABLE II. - COUNTERROTATION PROPELLER DESIGN CHARACTERISTICS

[ Value in parenthesis indicates F7/A3 configuration Total Activity Factor based on determination of A3 Activity Factor using A7 propeller diameter ]

\begin{tabular}{|c|c|c|}
\hline Propeller model configuration & F7/A3 & F7/A7 \\
\hline Number of blades (forward/aft) & $11 / 9$ & $11 / 9$ \\
Design Mach number/altitude, ft & $0.72 / 35,000$ & $0.72 / 35,000$ \\
Design tip speed, fps & 780 & 780 \\
Power loading, SHP/D & & 69 \\
Total Activity Factor & $3810(2775)$ & 3000 \\
\hline
\end{tabular}


TABLE III. - COUNTERROTATION PROPELLER TEST MATRIX AT ANGLE-OF-ATTACK

[ Test matrix conducted at maximum rotor spacing at Mach number 0.20 ]

\begin{tabular}{|c|c|c|c|c|}
\hline $\begin{array}{l}\text { Propeller model } \\
\text { configuration }\end{array}$ & $\begin{array}{l}\text { Blade number } \\
\text { (forward/aft) }\end{array}$ & $\begin{array}{l}\text { Blade angles } \\
\text { (forward/aft) }\end{array}$ & $\begin{array}{l}\text { Simulator } \\
\text { installation }\end{array}$ & $\begin{array}{l}\text { Propeller model } \\
\text { angles-of-attack }\end{array}$ \\
\hline \multirow{4}{*}{$\mathrm{F} 7 / \mathrm{A3}$} & \multirow{4}{*}{$11 / 9$} & $36.4 / 43.5$ & None & $0, \pm 8, \pm 16$ \\
\hline & & \multirow{3}{*}{$41.1 / 46.4$} & None & $0, \pm 8, \pm 16$ \\
\hline & & & Pylon & $0, \pm 8, \pm 12$ \\
\hline & & & Pylon/fuselage & $0, \pm 8, \pm 12$ \\
\hline \multirow{3}{*}{$\mathrm{F} 7 / \mathrm{A} 7$} & \multirow{3}{*}{$11 / 9$} & $36.4 / 36.5$ & None & $0, \pm 8,-16$ \\
\hline & & \multirow{2}{*}{$41.1 / 39.4$} & None & $0,-8,-16$ \\
\hline & & & Pylon/fuselage & $0, \pm 8, \pm 12$ \\
\hline
\end{tabular}

TABLE IV. - COUNTERROTATION PROPELLER TAKE-OFF TARGET OPERATING POINTS

\begin{tabular}{|c|c|c|c|c|c|c|}
\hline $\begin{array}{c}\text { Propeller } \\
\text { model } \\
\text { configuration }\end{array}$ & $\begin{array}{c}\text { Number of blades } \\
\text { (forward/aft) }\end{array}$ & $\begin{array}{c}\text { Blade angles } \\
\text { (forward/aft) }\end{array}$ & $\begin{array}{c}\text { Total power } \\
\text { coefficient, } \\
\text { PQA }\end{array}$ & Advance ratio, & $\begin{array}{c}\text { Tip speed, } \\
\text { fps }\end{array}$ & $\begin{array}{c}\text { Power loading } \\
\text { parameter, } \\
\mathrm{J}_{1}\end{array}$ \\
\hline \multirow{2}{*}{ F7/A3 } & $11 / 9$ & $36.4 / 43.5$ & 2.444 & .861 & 815 & 3.829 \\
\cline { 2 - 7 } & & $41.1 / 46.4$ & 3.432 & .923 & 760 & 4.365 \\
\hline F7/A7 & $11 / 9$ & $36.4 / 36.5$ & 2.444 & .861 & 815 & 3.829 \\
\hline
\end{tabular}




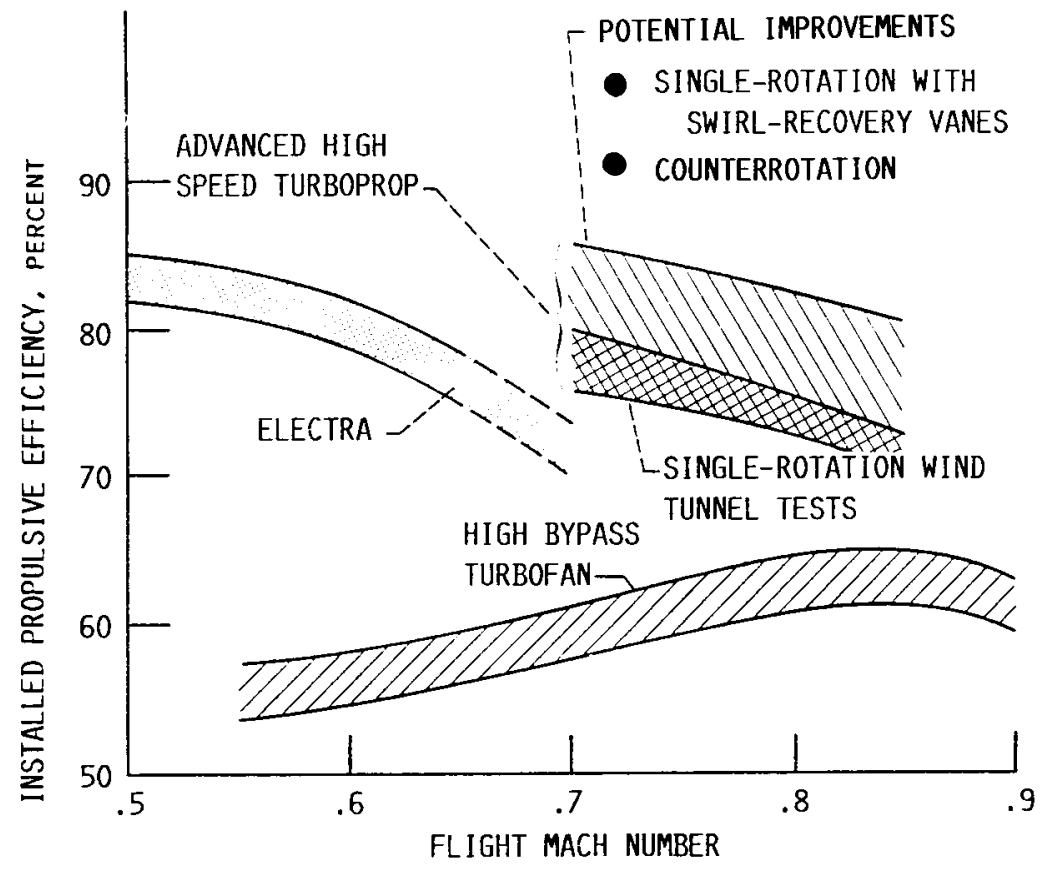

FIGURE 1. - INSTALLED PROPULSIVE EFFICIENCY TRENDS OF ADVANCED TURBOPROPS COMPARED WITH EQUIVALENT TECHNOLOGY TURBOFANS.

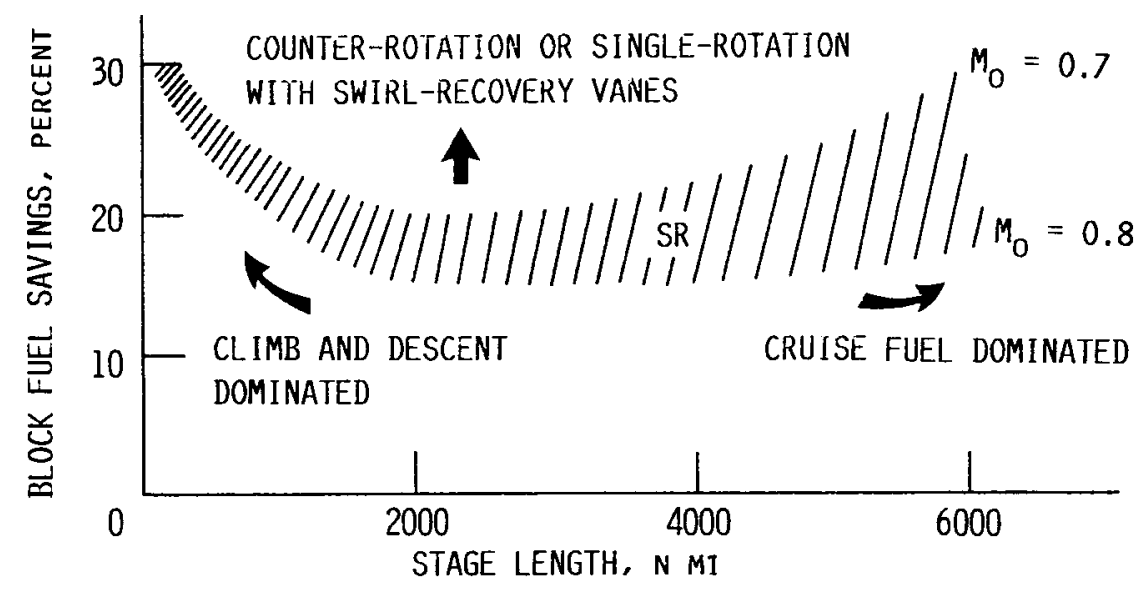

FIGURE 2. - FUEL SAVINGS TRENDS OF ADVANCED TURBOPROP AIRCRAFT OVER COMPARABLE TURBOFAN AIRCRAFT. 


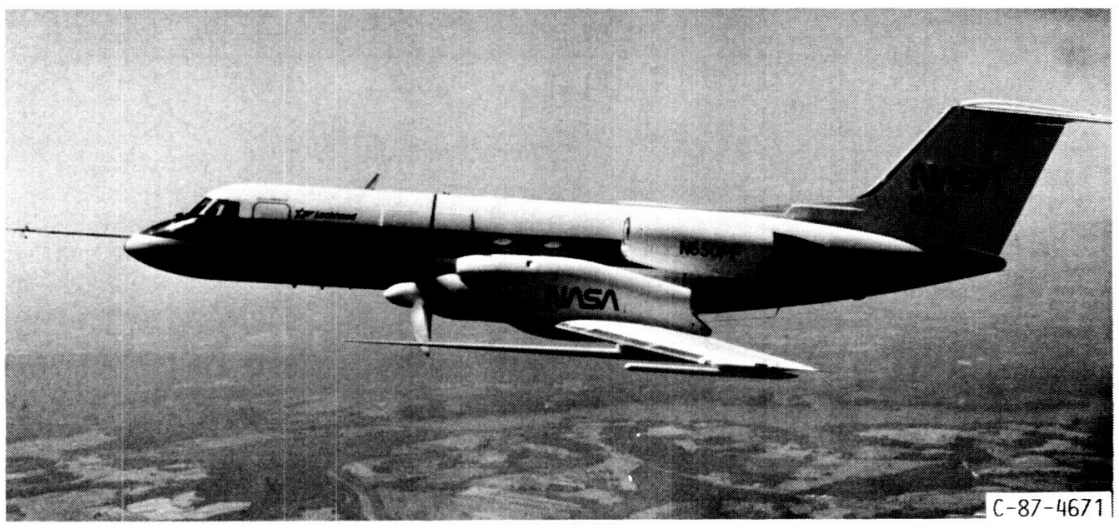

(a) NASA PTA INSTALLED ON LOCKHEED GII AIRCRAFT.

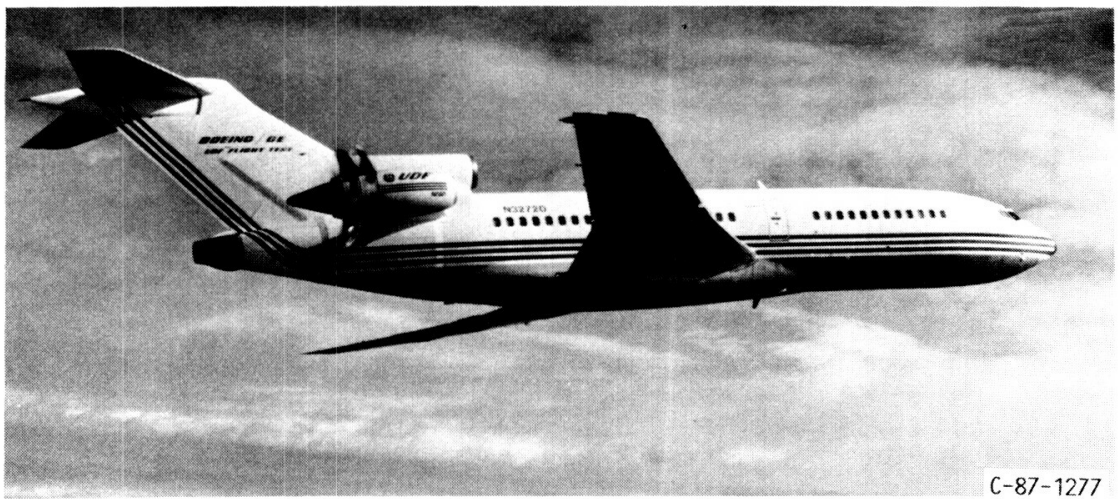

(b) NASA/GE UDF INSTALLED ON BOEING 727 AIRCRAFT.

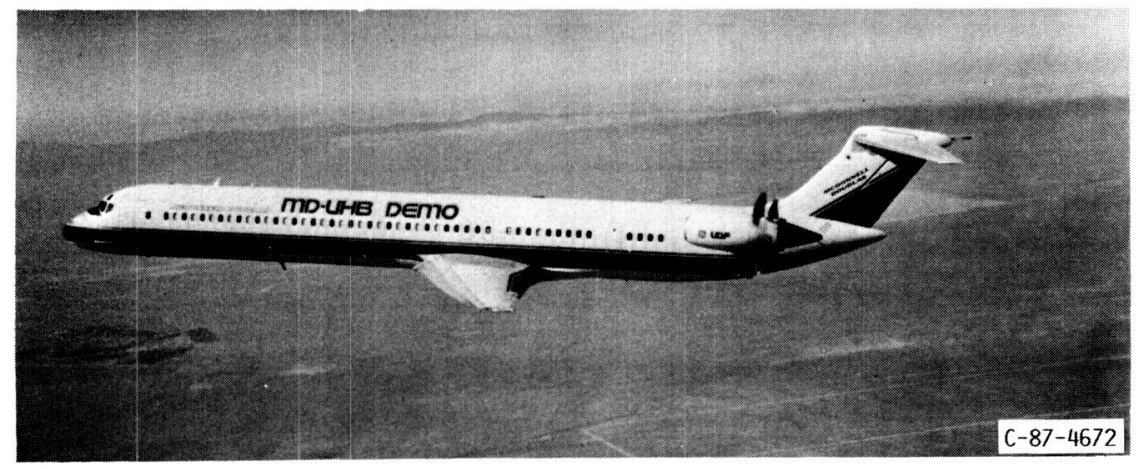

(c) NASA/GE UDF INSTALLED ON MCDONNELL DOUGLAS MD-80 AIRCRAFT. FIGURE 3. - ADVANCED PROPELLER CONCEPTS IN FLIGHT TEST.<smiles>[CH]1C=CC1</smiles> 


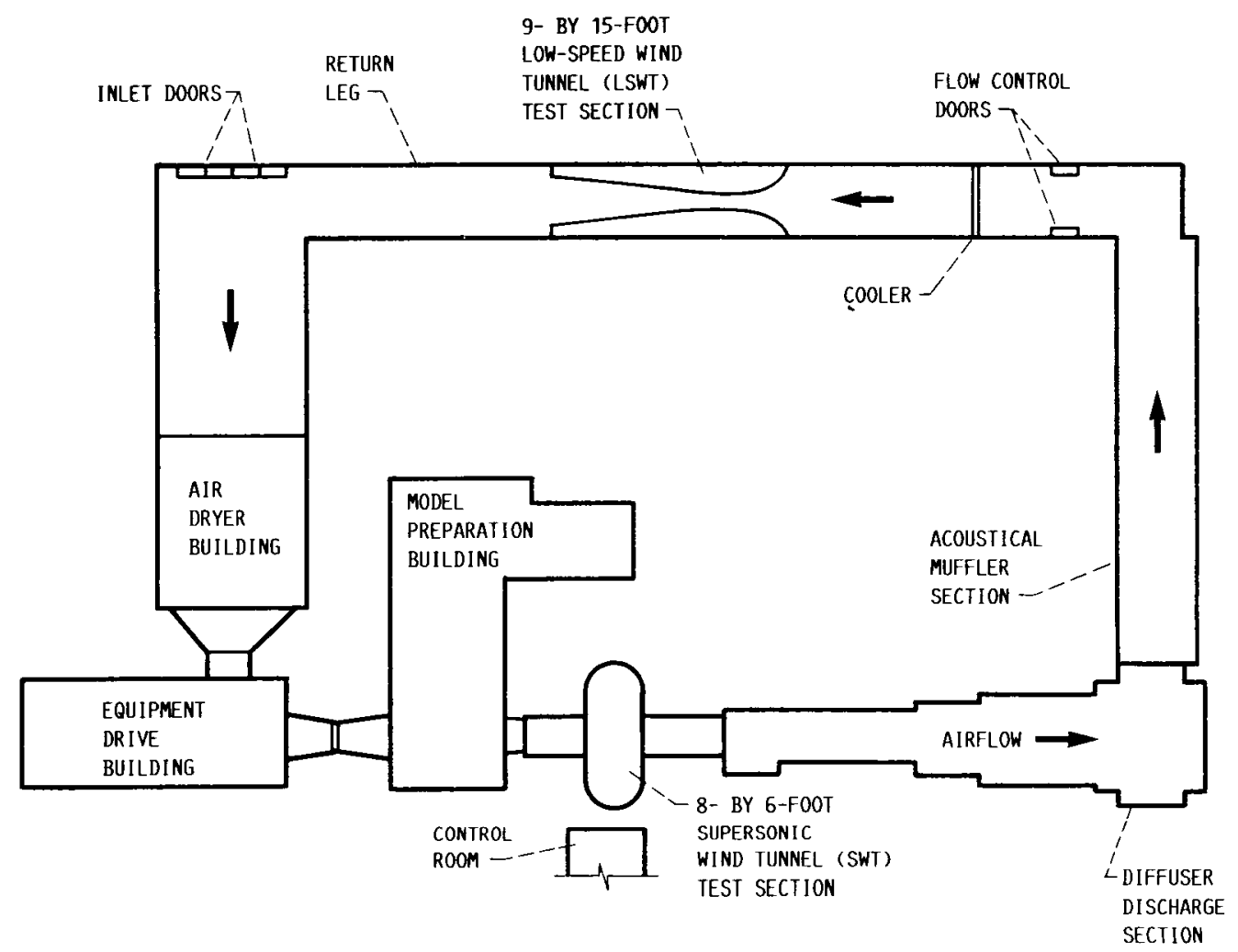

(a) OVERALL PLAN VIEW.

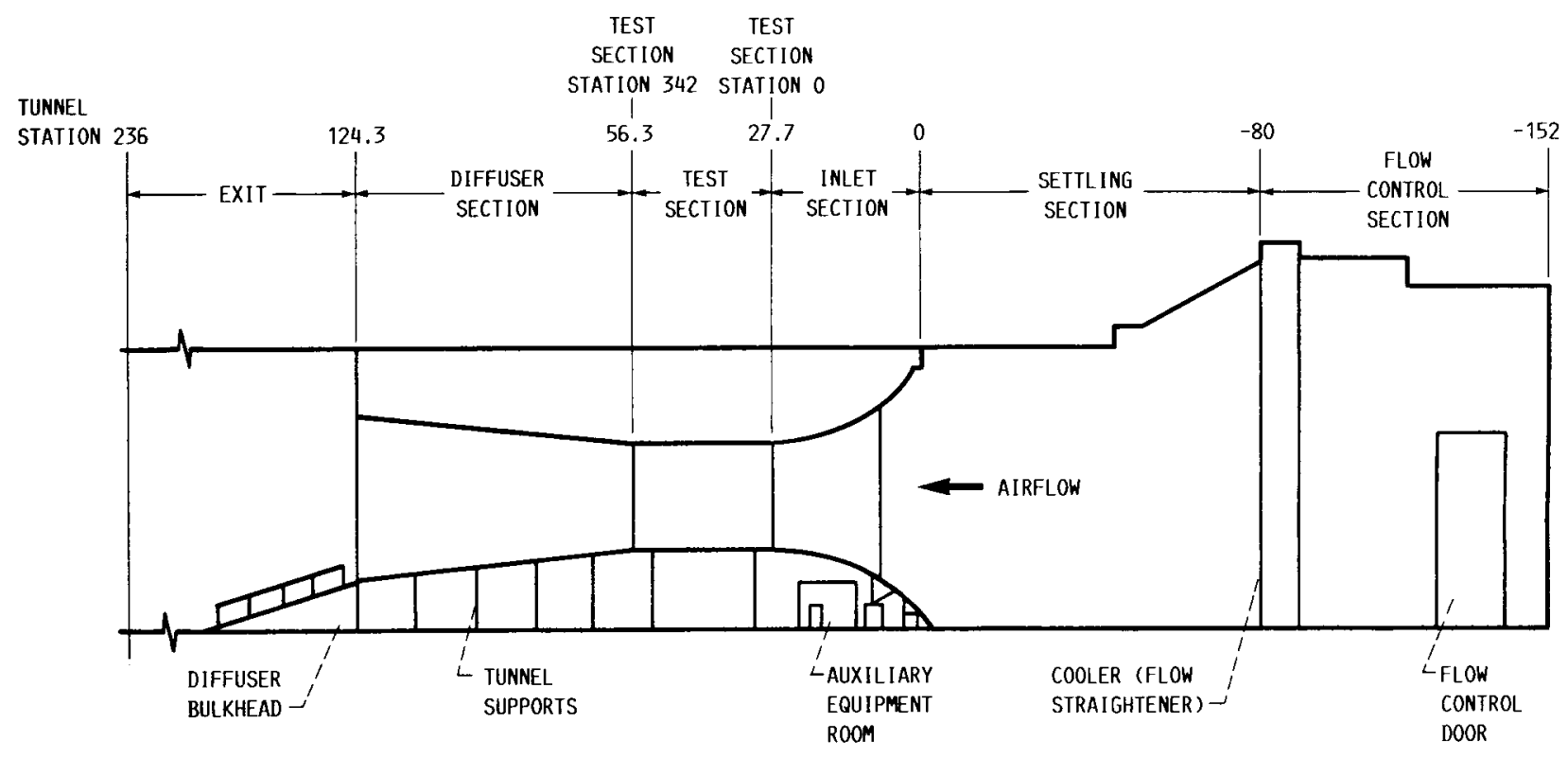

(b) SCHEMATIC ELEVATION VIEW OF 9- BY 15-FOOT SECTION.

FIGURE 4. - GEOMETRY OF NASA LEWIS RESEARCH CENTER 9- BY 15-FO0T LOW-SPEED WIND TUNNEL. 


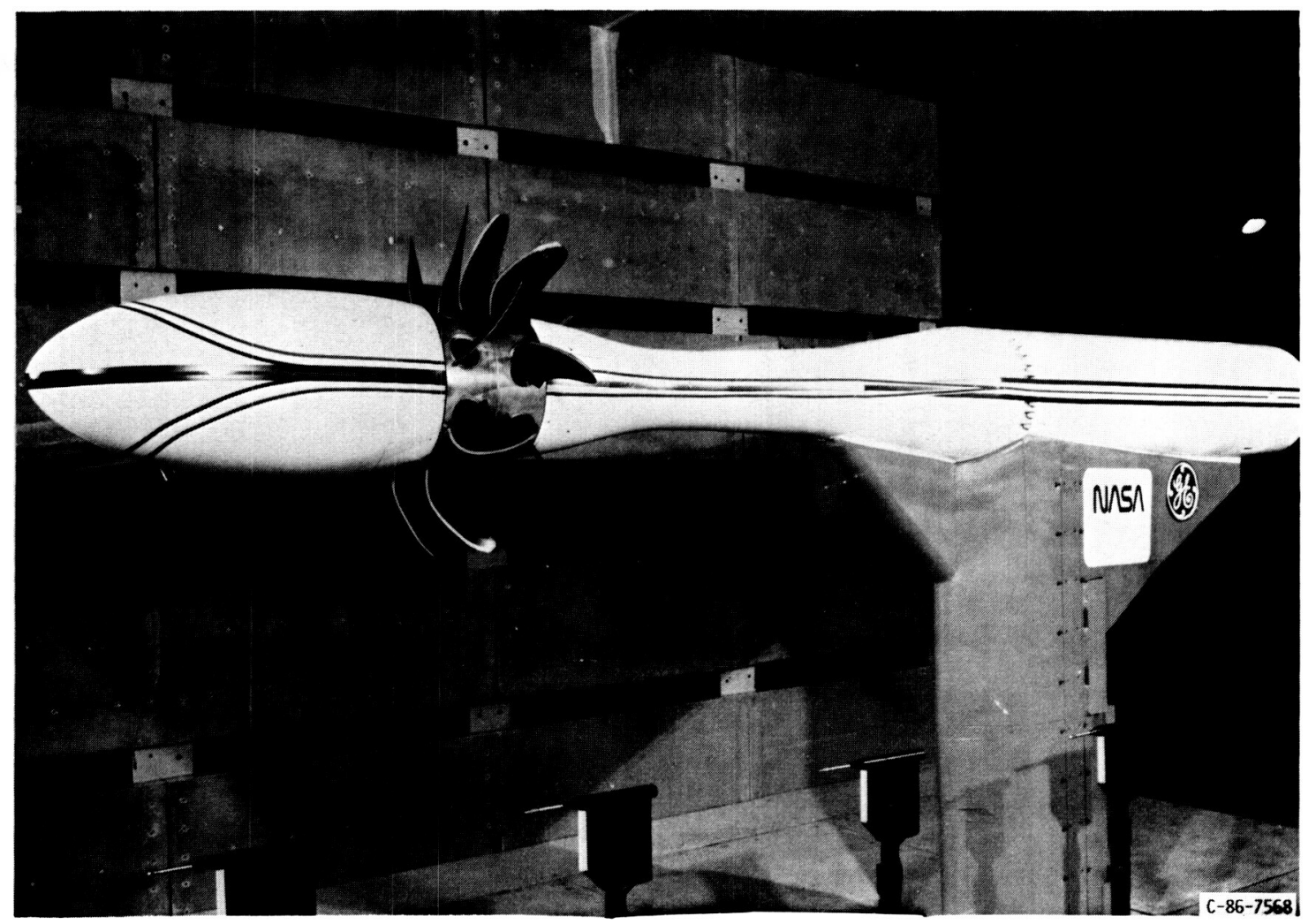

FIGURE 5. - NASA/GE COUNTERROTATION PROPELLER IEST RIG (CPR/PIR) AND PROPELLER MODEL INSTALLED IN NASA LEWIS 9- BY 15- FOOT LOW-SPEED WIND TUNNEL.

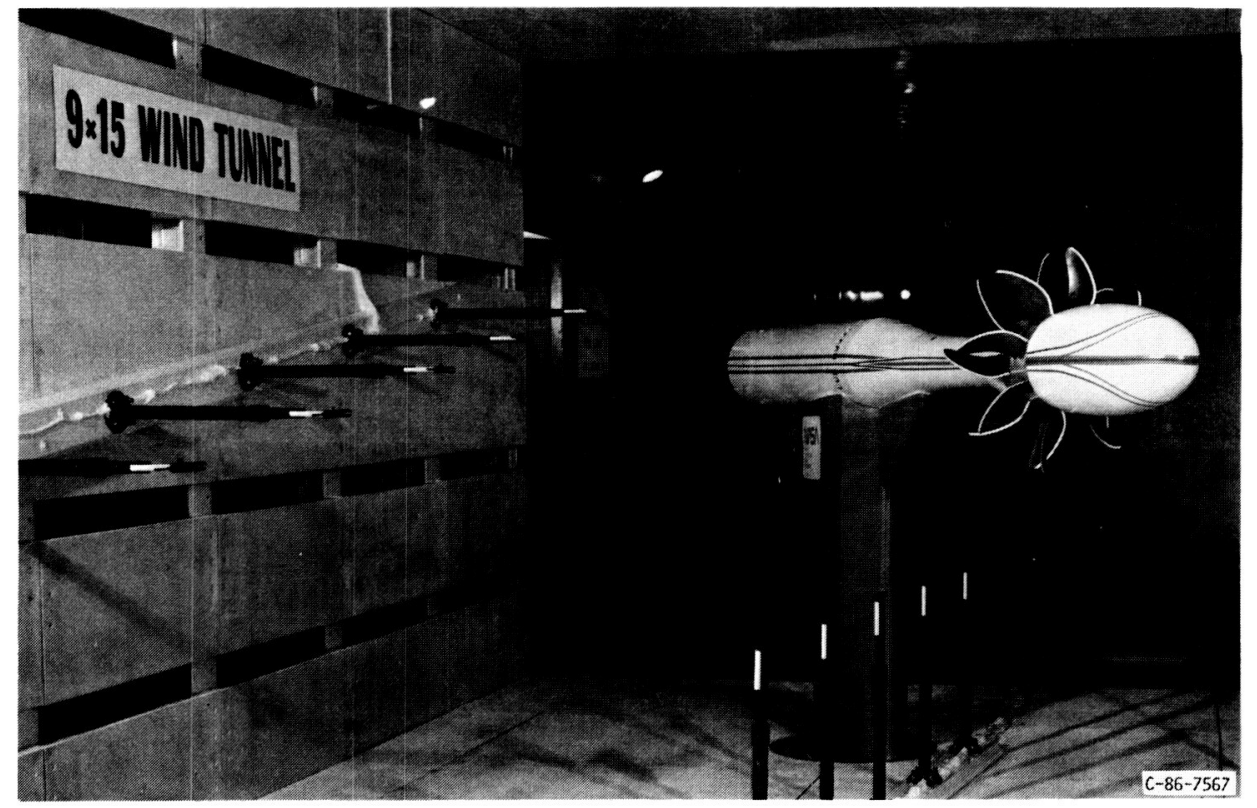

FigURE 6. - NASA/ge CPR/PIR ANI PROPEIIER MODEL. AI NEGATIVE ANGLE-OF-ATIACK IN WINI) TUNNEL teSt SECTION. 


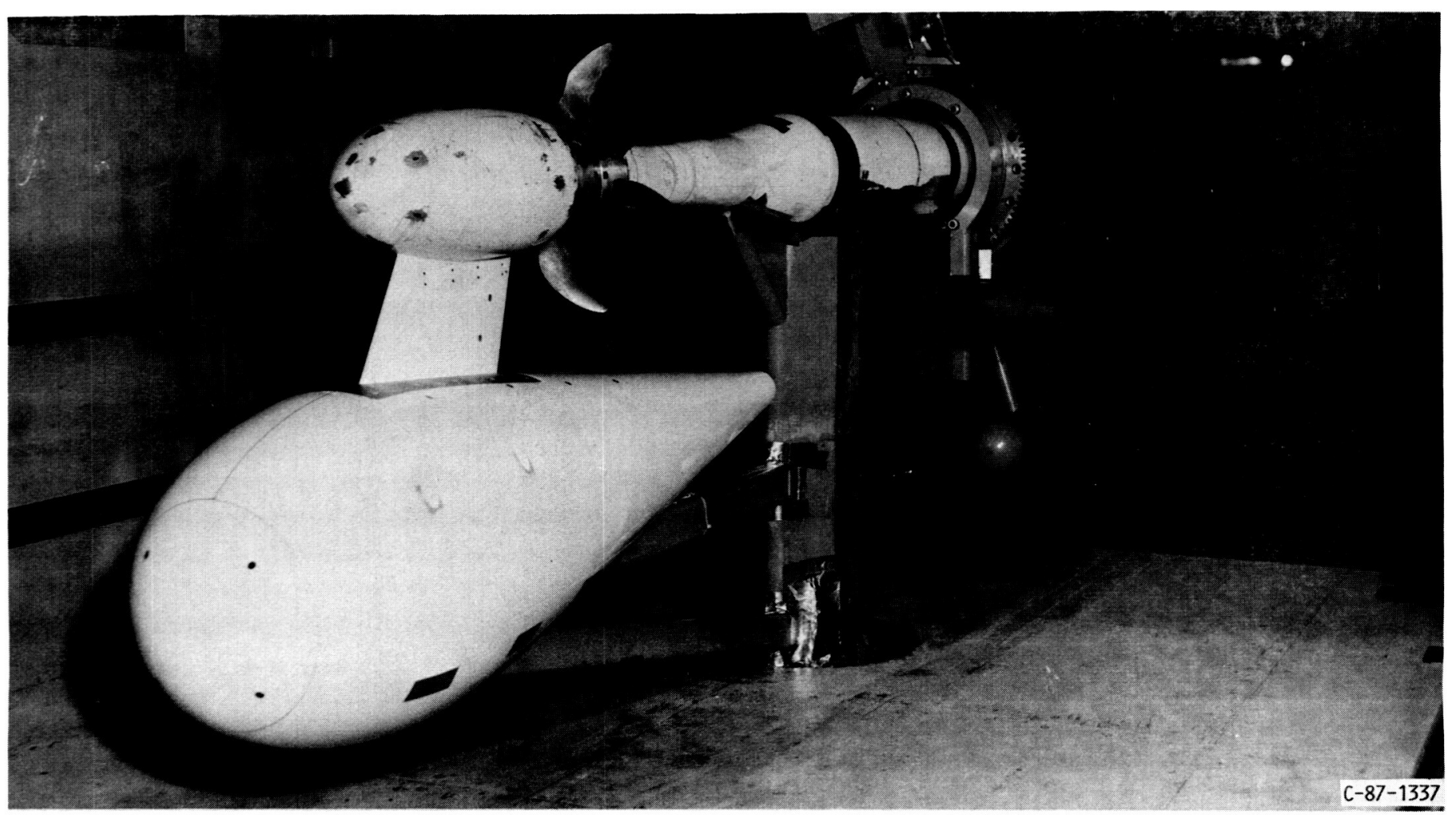

(a) OVERALL VIEW OF PYLON/FUSELAGE SIMULATORS INSTALLED ON CRP/PTR.

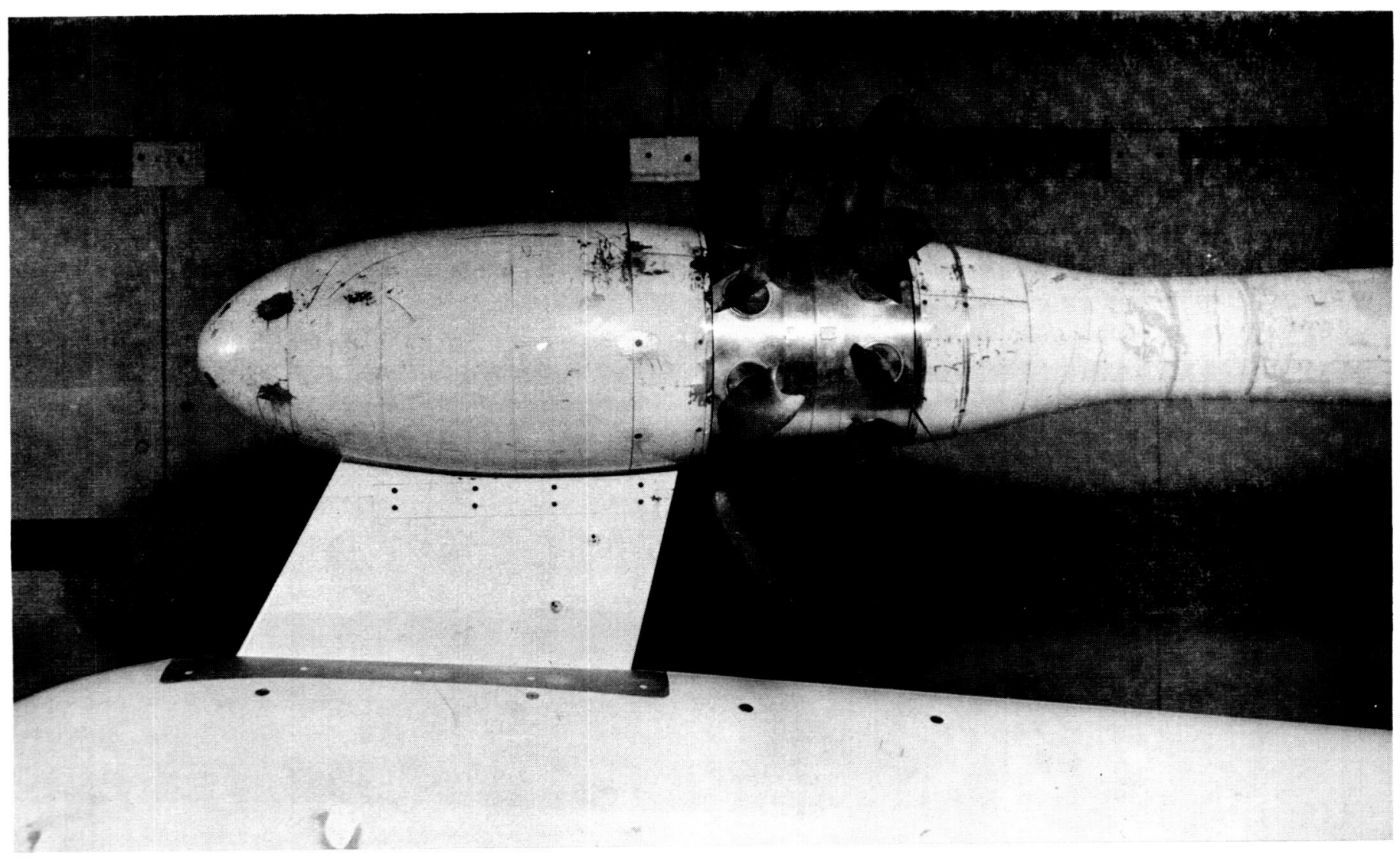

(b) CLOSEUP VIEW OF CRP/PTR FOREBODY AND AIRCRAFT PYLON/FUSELAGE SIMULATOR.

FIGURE 7. - COUNIERROTAIION PROPELLER MODEL WITH AIRCRAFT FUSELAGE AND ENGINE SUPPORT PYLON SIMULATORS INSTALLED. 


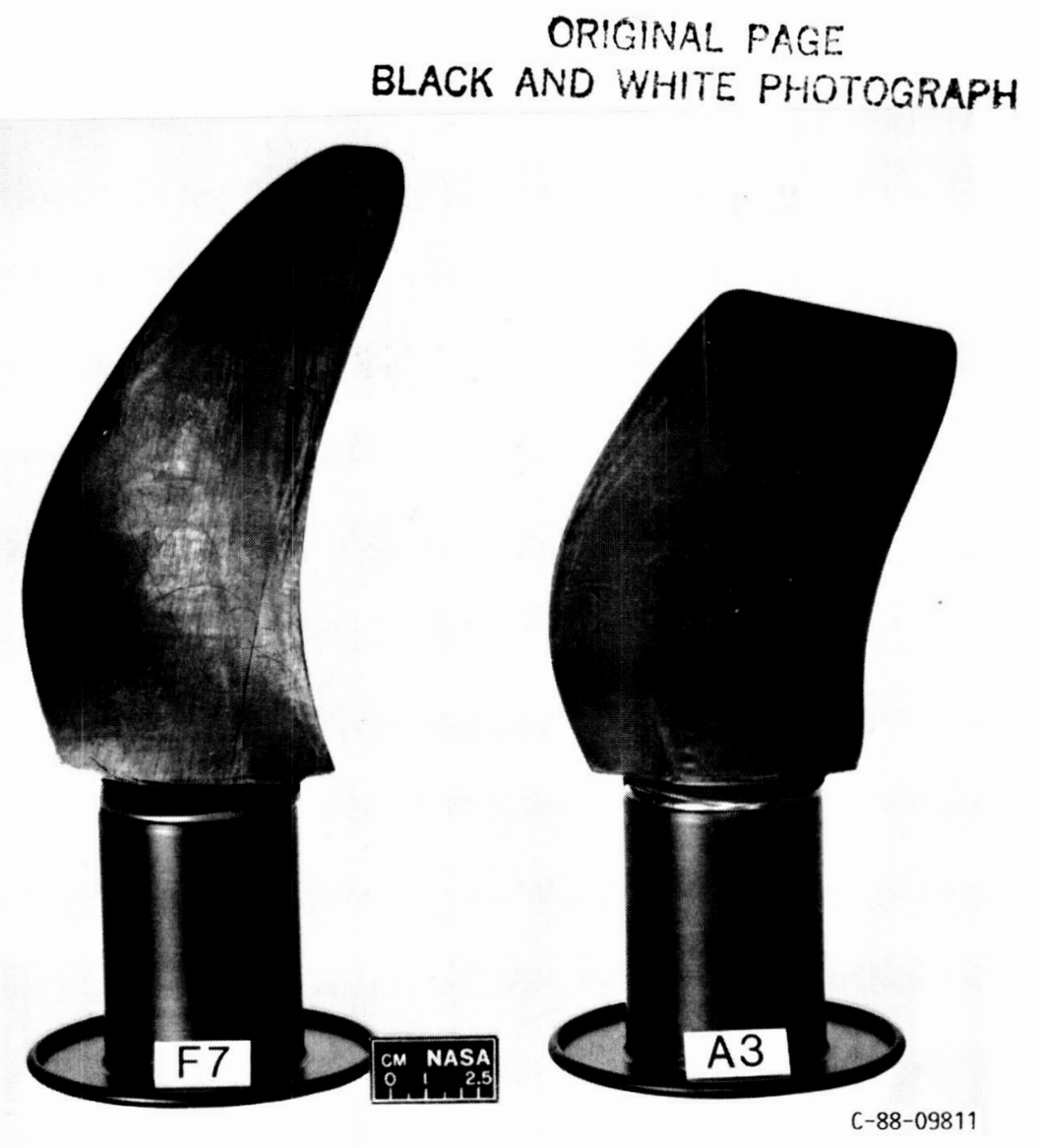

(a) F7/A3 PROPELLER CONFIGURATION BLADES.

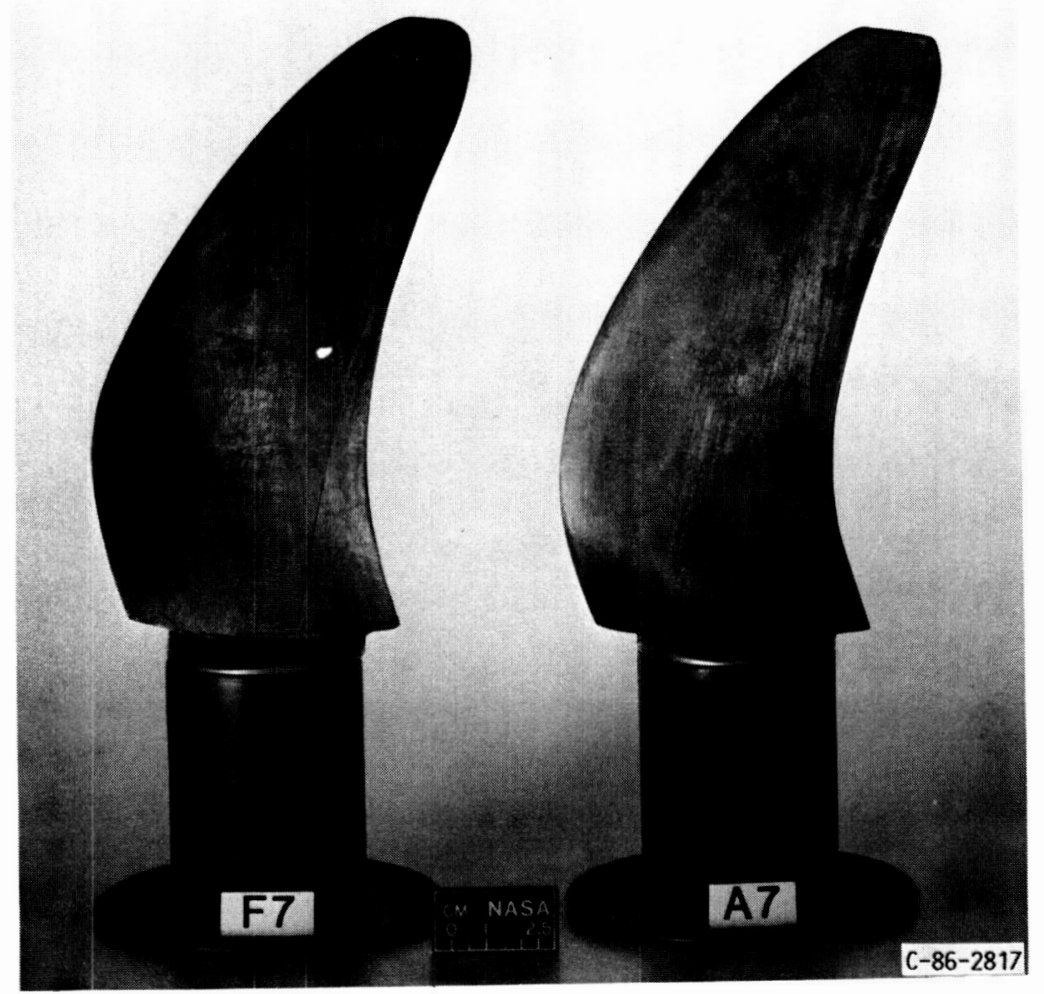

(b) F7/A7 PROPELLER CONFIGURATION BLADES.

FIGURE 8. - COUNTERROTATION PROPELLER MODEL BLADES TESTED. 


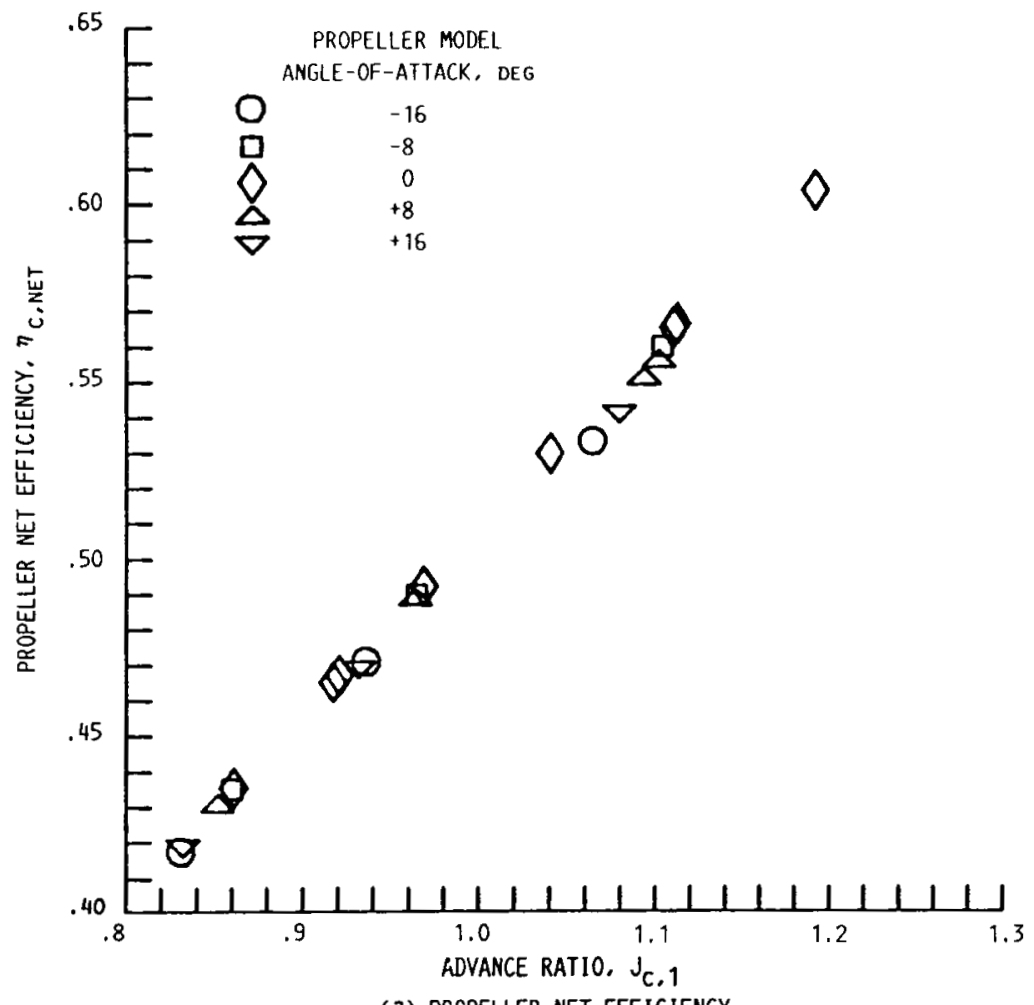

(a) PROPELLER NET EFFICIENCY.

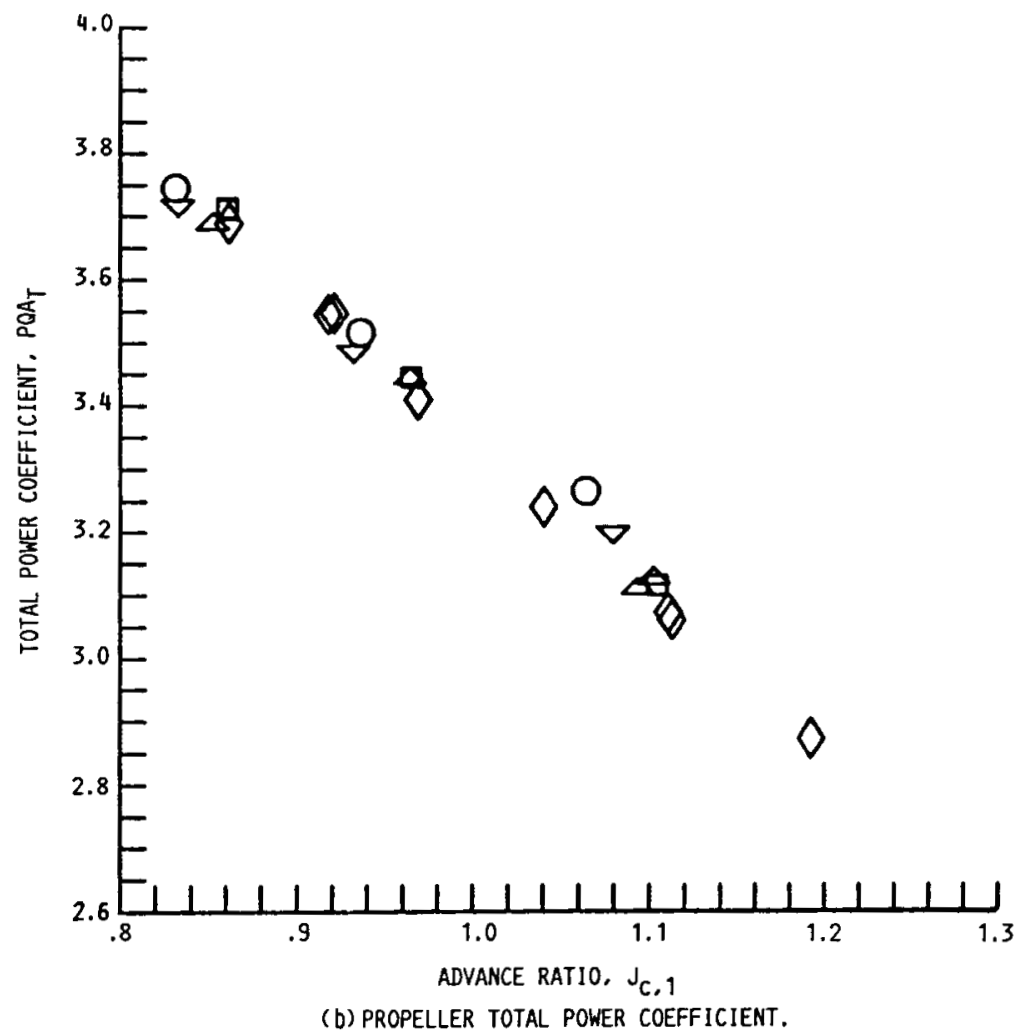

FIGURE 9. - OVERALL PERFORMANCE OF F7/A3 11/9 COUNTERROTATION PROPELLER CONFIGURATION WITH ANGLE-OF-ATTACK AT MACH NUMBER 0.20 (PROPELLER BLADE ANGLES OF $41,1 / 46.4$. TAKE-OFF TARGET POWER LOADING OF 4.365).

28 


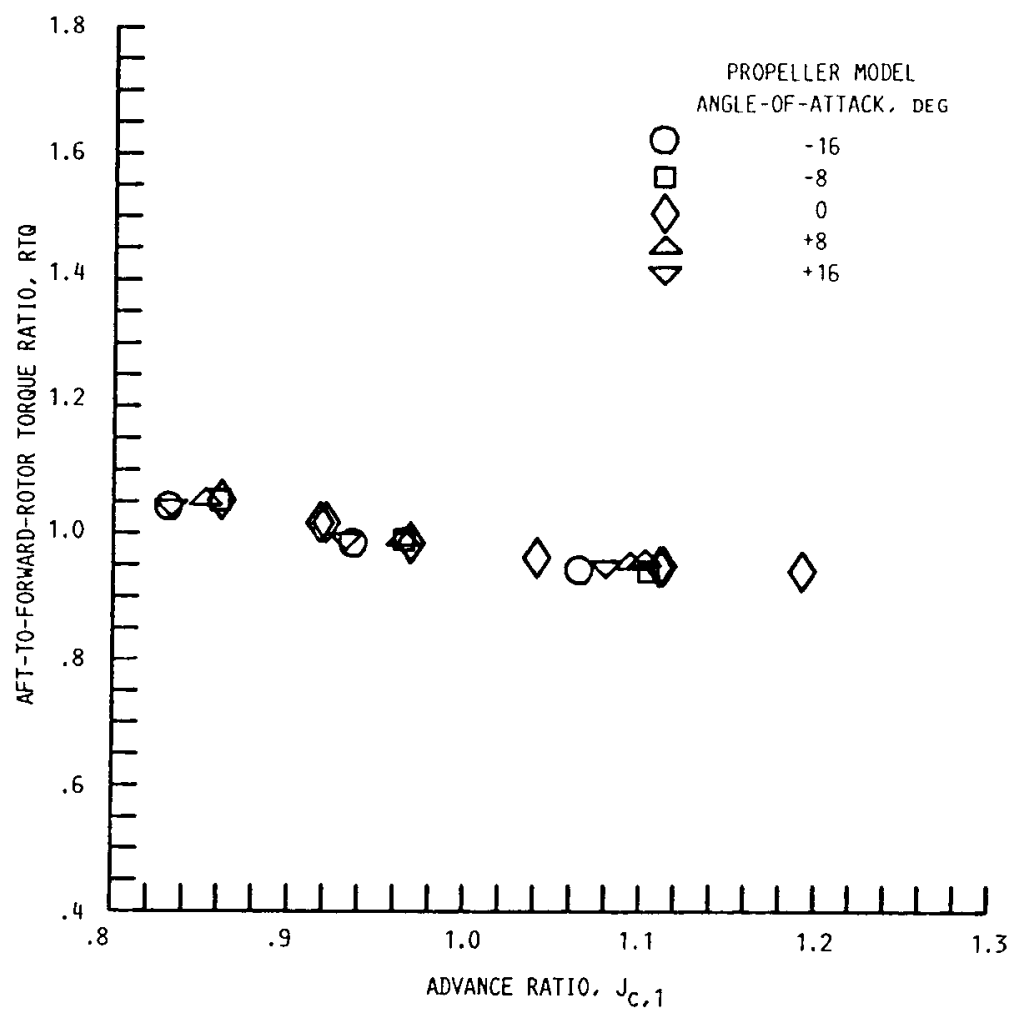

(c) PROPELLER ADVANCE RATIO.

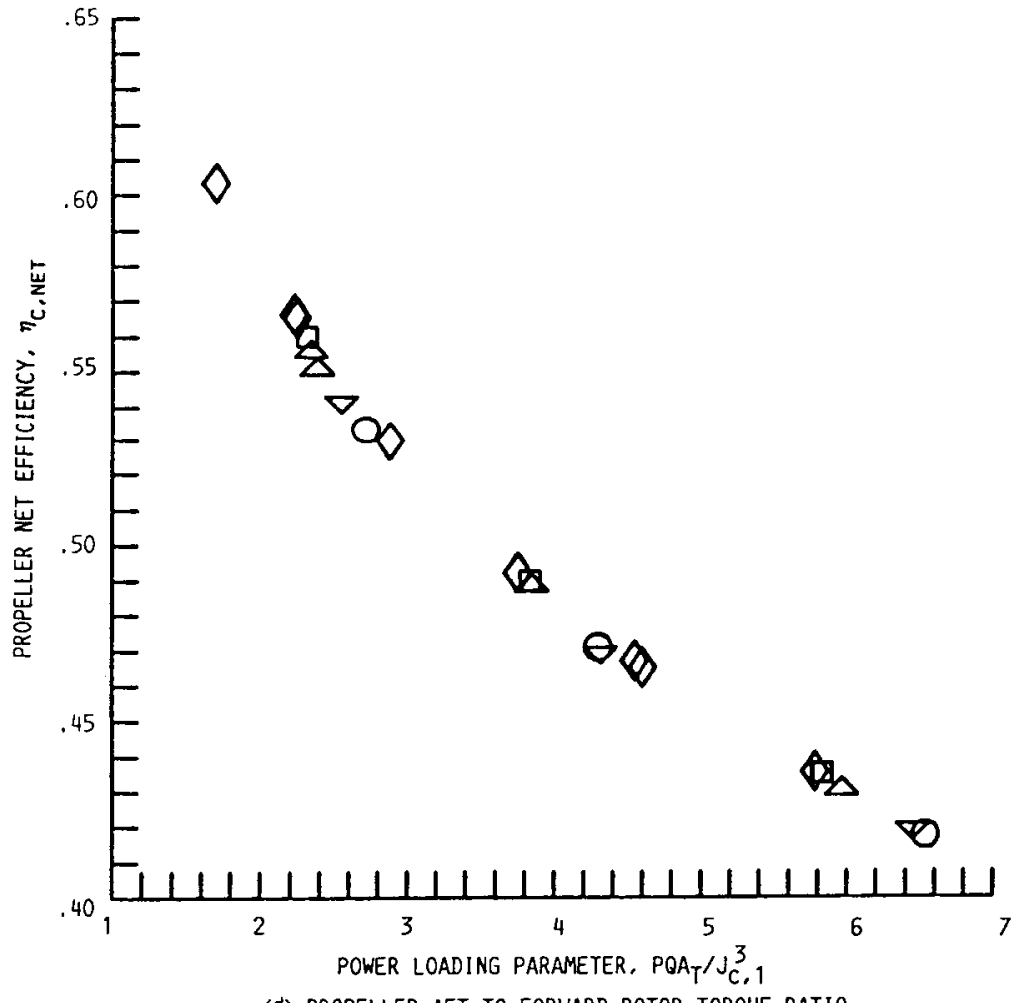

(d) PROPELLER AFT-TO-FORWARD-ROTOR TORQUE RATIO.

FIGURE 9. - CONCLUDED.

29 


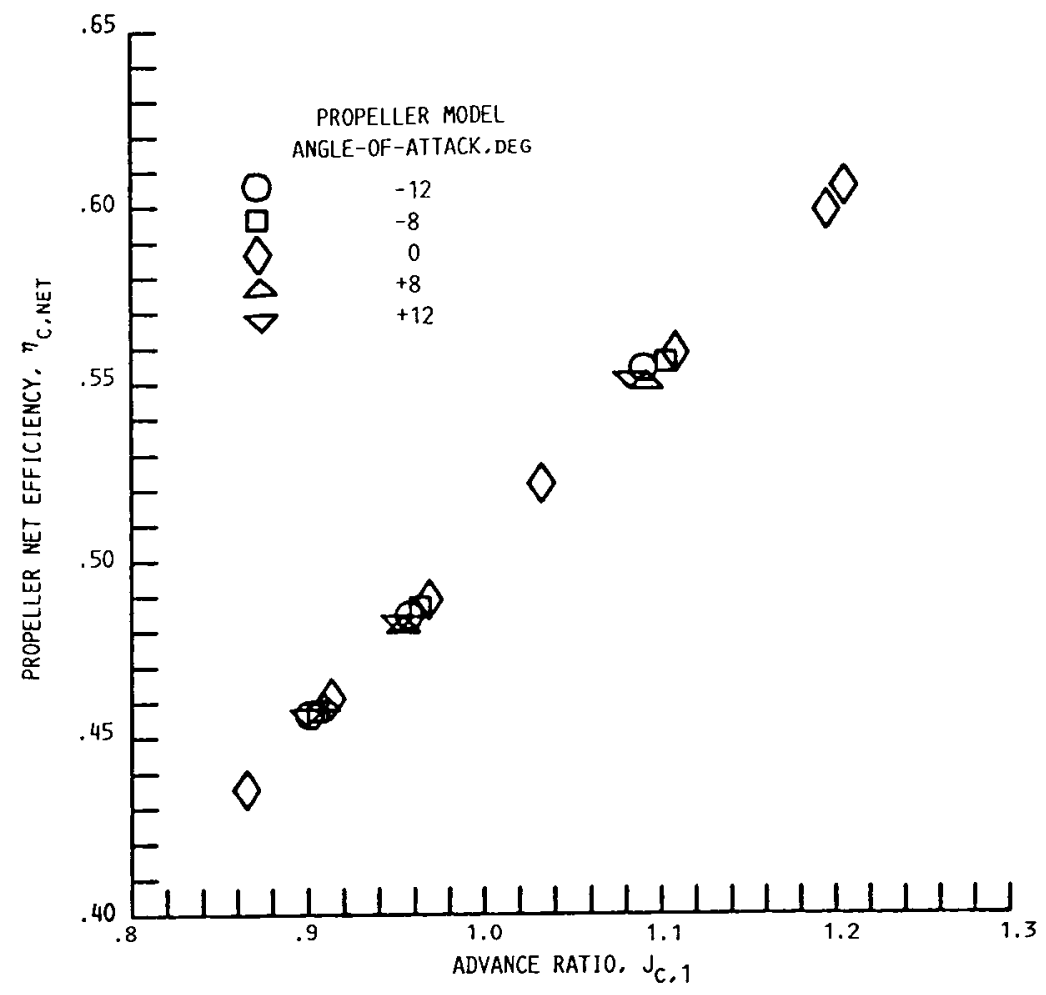

(a) PROPELLER NET EFFICIENCY.

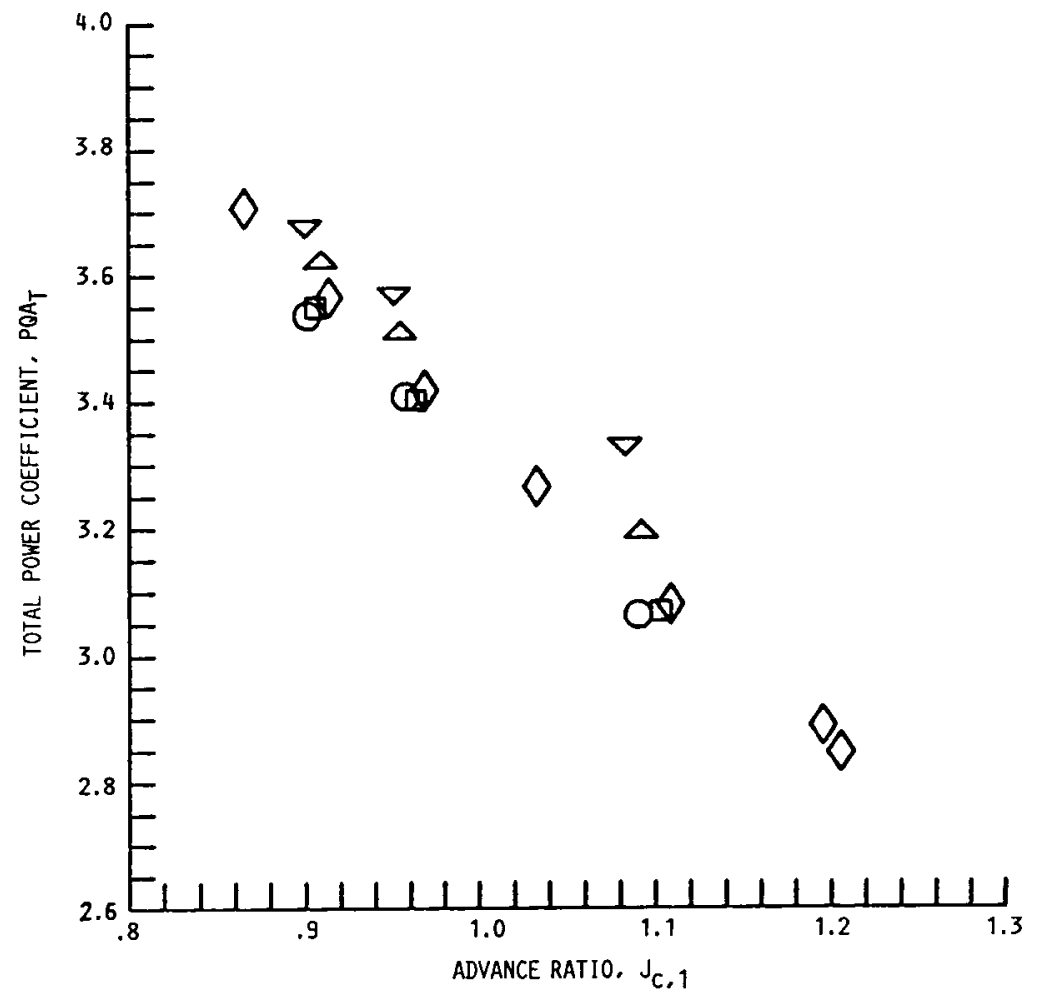

(b) PROPELLER TOTAL POWER COEFFICIENT.

FIGURE 10. - OVERALL PERFORMANCE OF F7/A3 $11 / 9$ COUNTERROTATION PROPELLER CONFIGURATION WITH ANGLE-OF-ATTACK AT MACH NUMBER 0.20 WITH ENGINE SIMULATOR INSTALLED ON CRP/PTR (PROPELLER BLADE ANGLE OF $41.1 / 64.4$, TAKE-OFF TARGET POWER LOADING PARAMETER OF 4.365). 


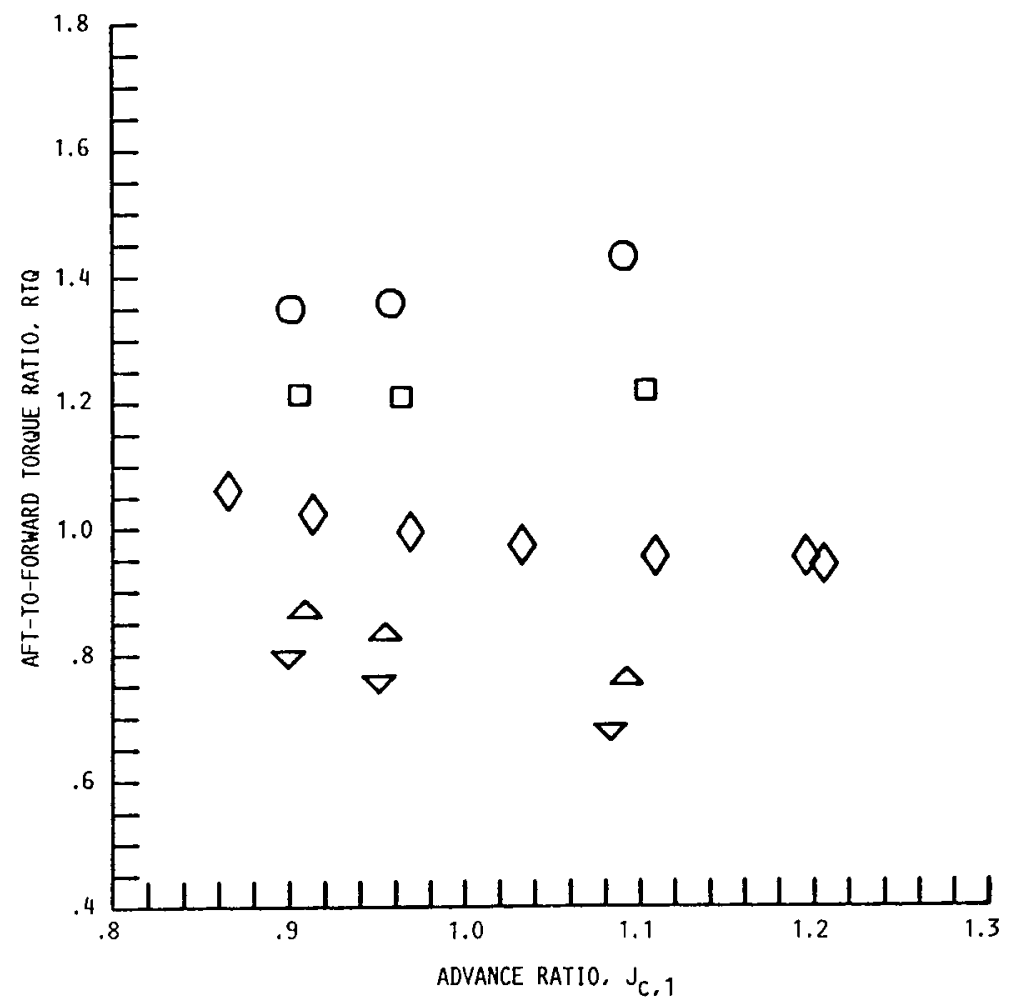

(c) PROPELLER ADVANCE RATIO.

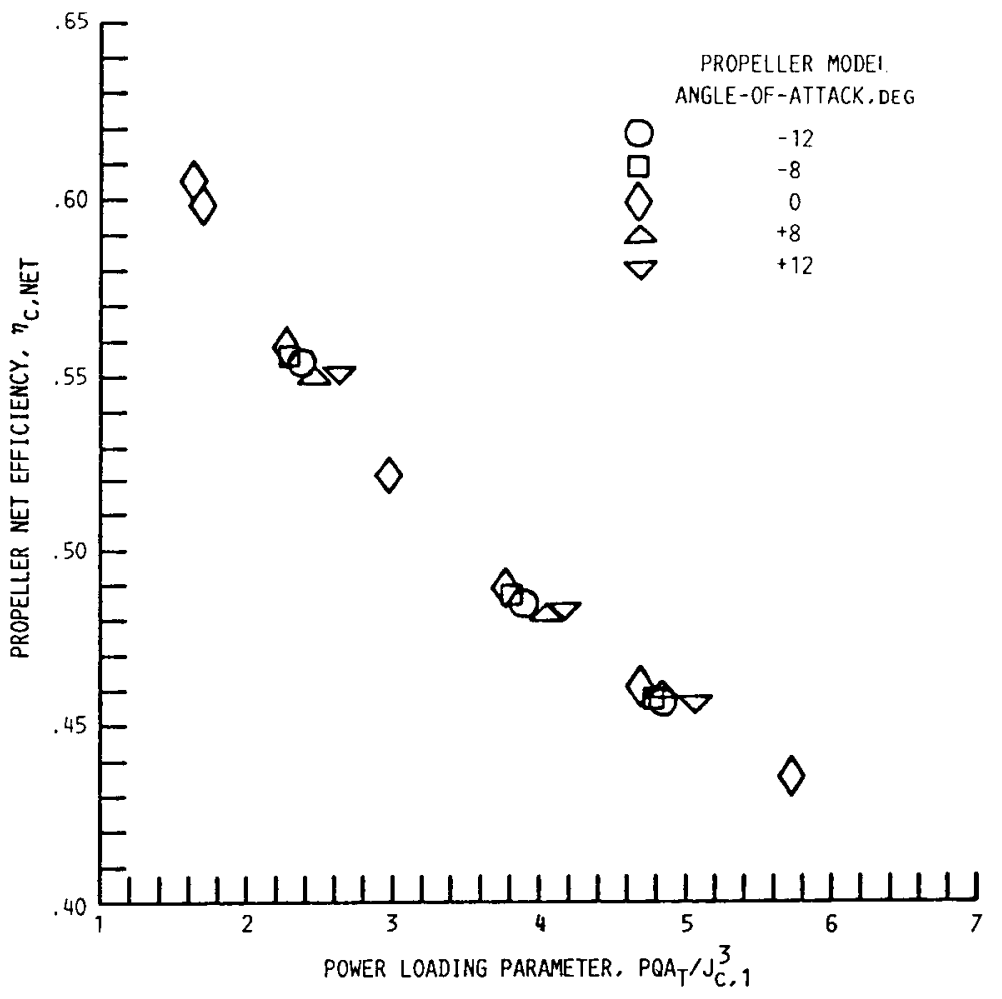

(d) PROPELLER AFT-TO-FORWARD-ROTOR TORQUE RATIO.

FIGURE 10 . CONCLUDED.

31 


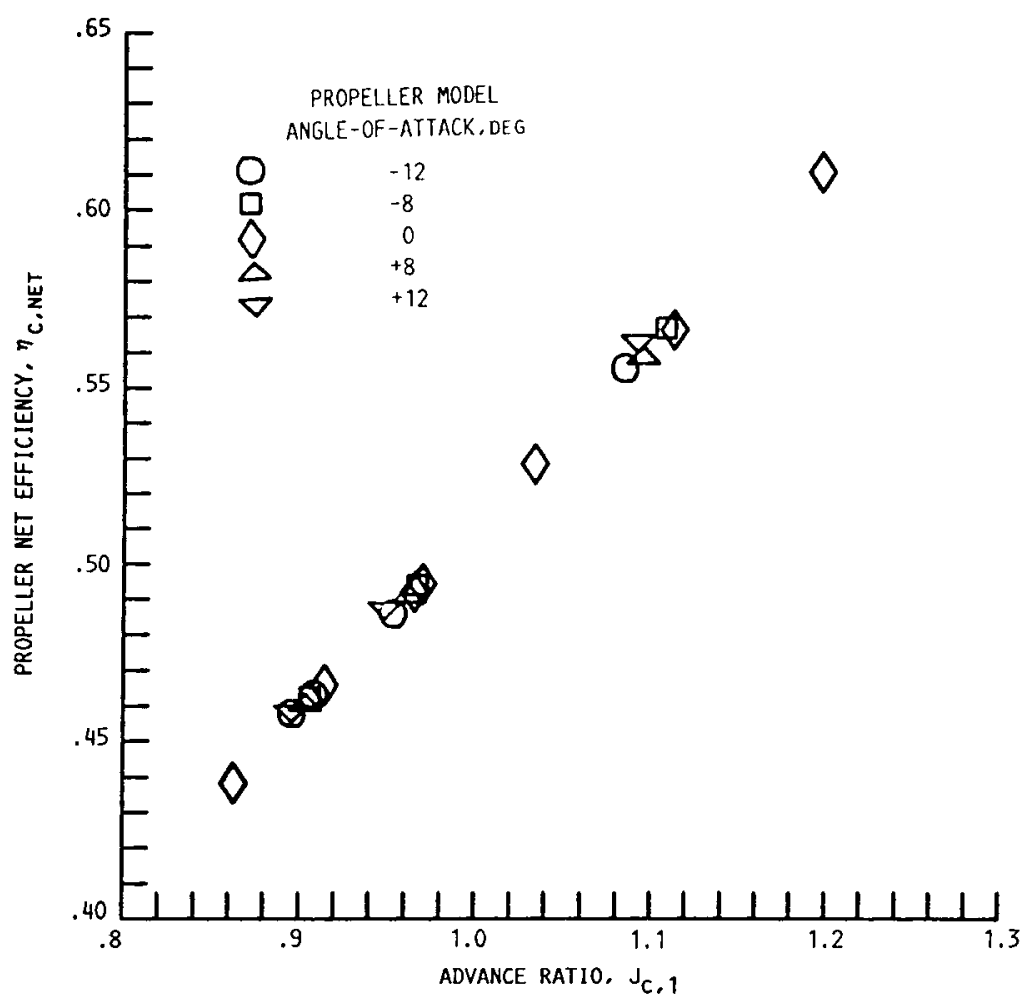

(a) PROPELLER NET EFFICIENCY.

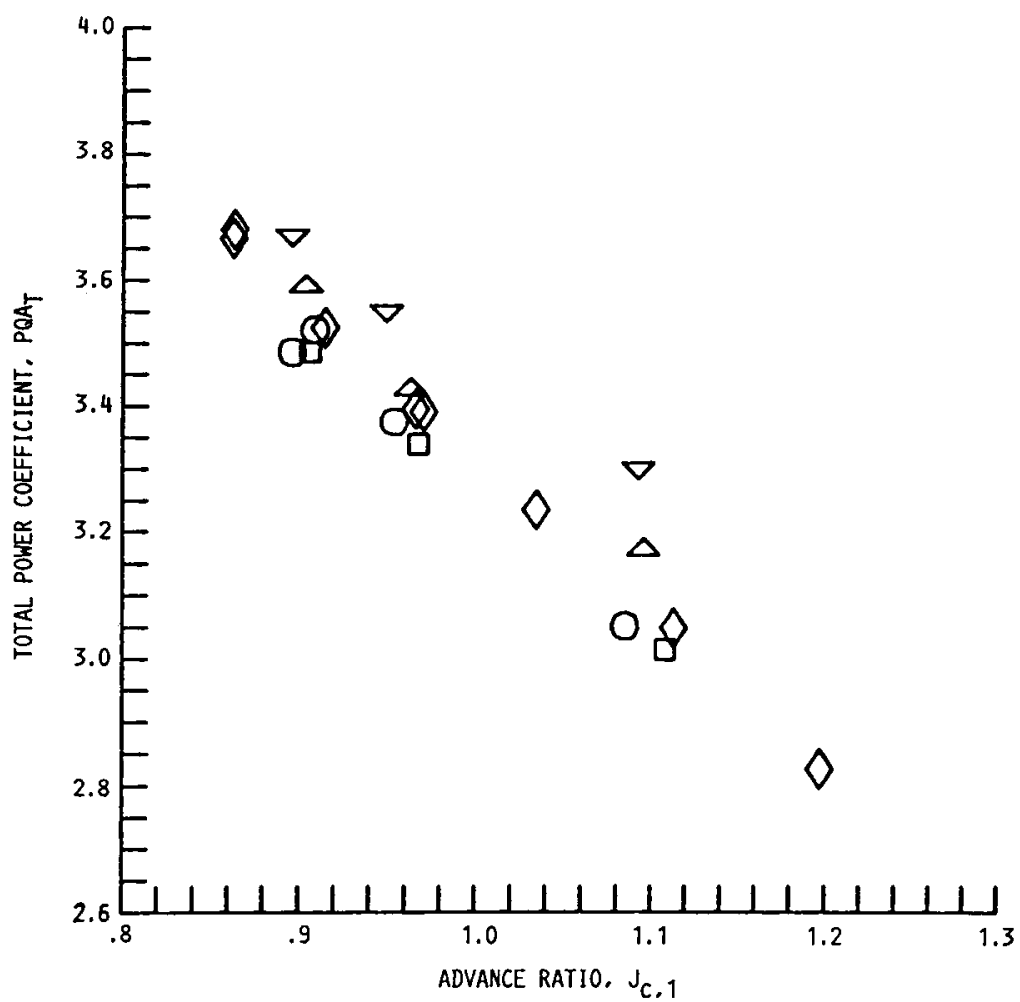

(b) PROPELLER TOTAL POWER COEFFICIENT.

FIGURE 11. - OVERALL PERFORMANCE OD F7/A3 11/9 COUNTERROTATION PROPELLER CONFIGURATION WITH ANGLE-OF-ATTACK AT MACH NUMBER 0.20 WITH ENGINE PYLON AND AIRCRAFT FUSELAGE SIMULATOR INSTALLED ON CRP/PTR (PROPELLER BLADE ANGLES OF $41,1 / 46.4$. TAKE-OFF TARGET POWER LOADING PARAMETER OF 4.365). 

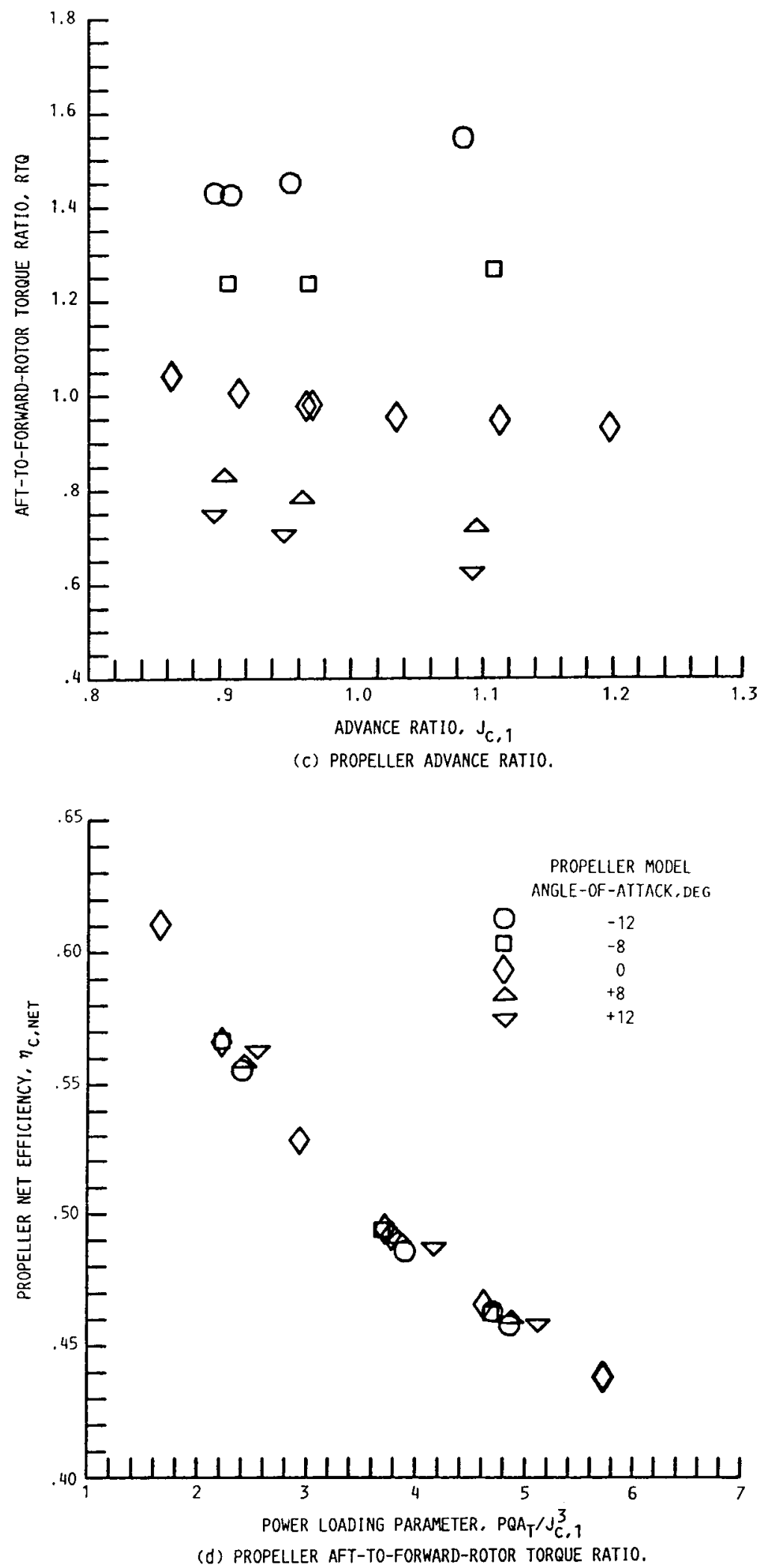

FIGURE 11. - CONCLUDED. 


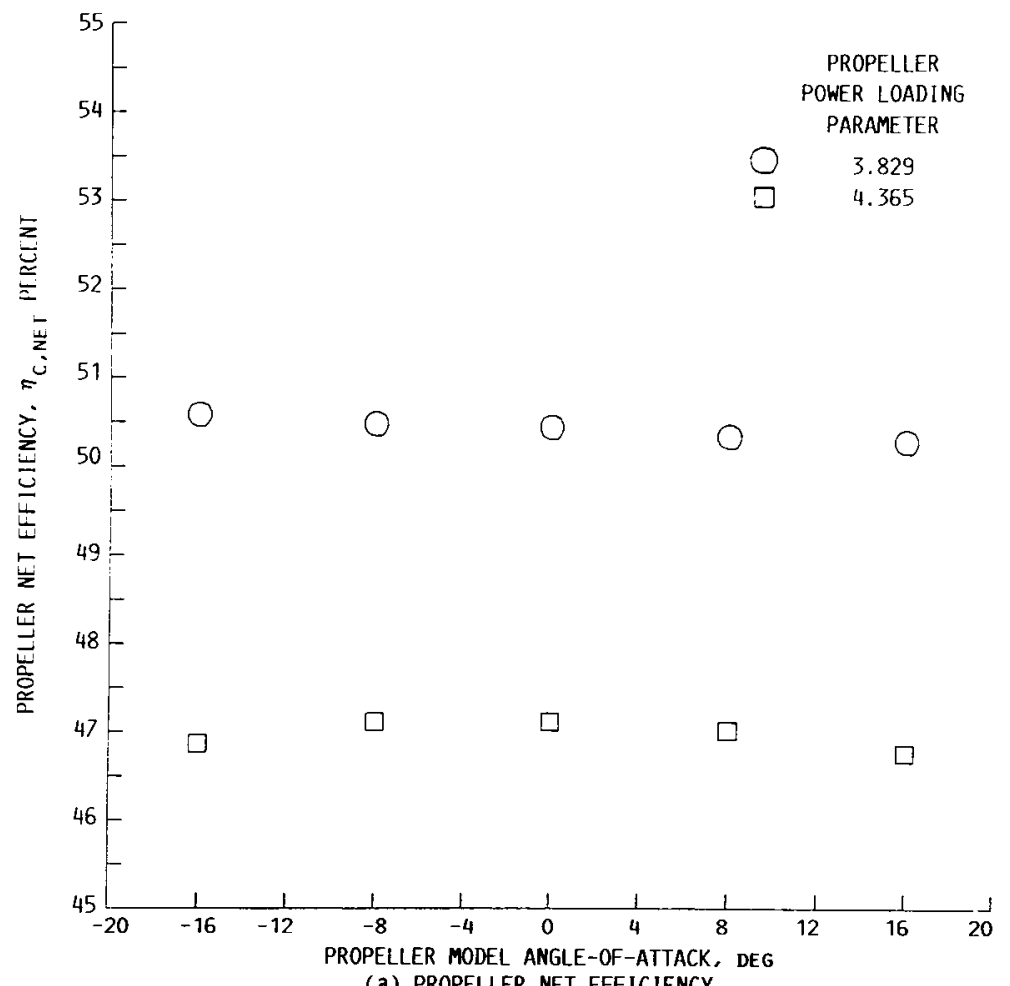

(a) PROPELLER NET EFFICIENCY.

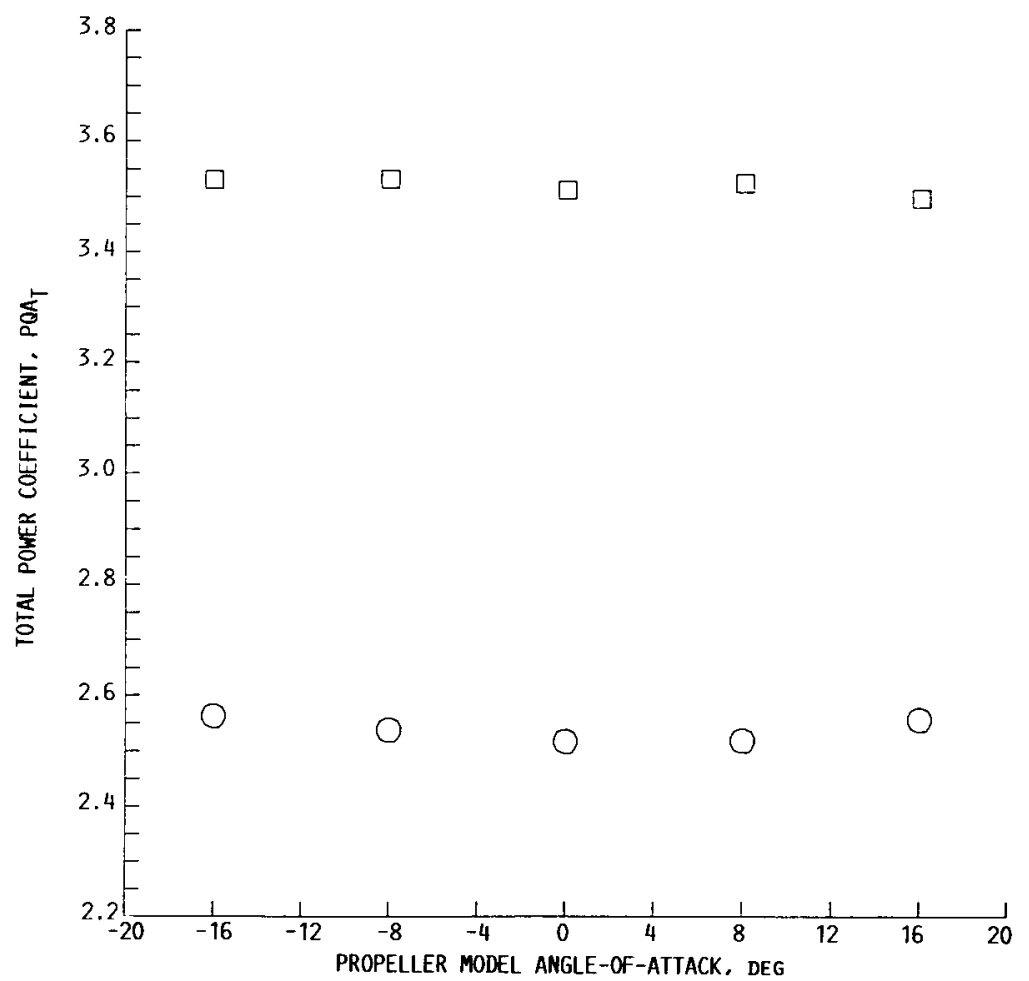

(b) PROPELLER TOTAL POWER COEFFICIENT.

FIGURE 12. - PERFORMANCE OF F7/A3 11/9 PROPELLER CONFIGURATION WITH ANGLE-OF-ATTACK WITHOUT PYLON OR FUSELAGE SIMULATORS AT CONSTANT TAKE-OFF POWER LOADING PARAMETERS 3.829 AND 4.365 AT MACH NUMBER

0.20 (PROPELLER BLADE ANGLES OF 36.4/43.5 AND 41.1/46.4). 


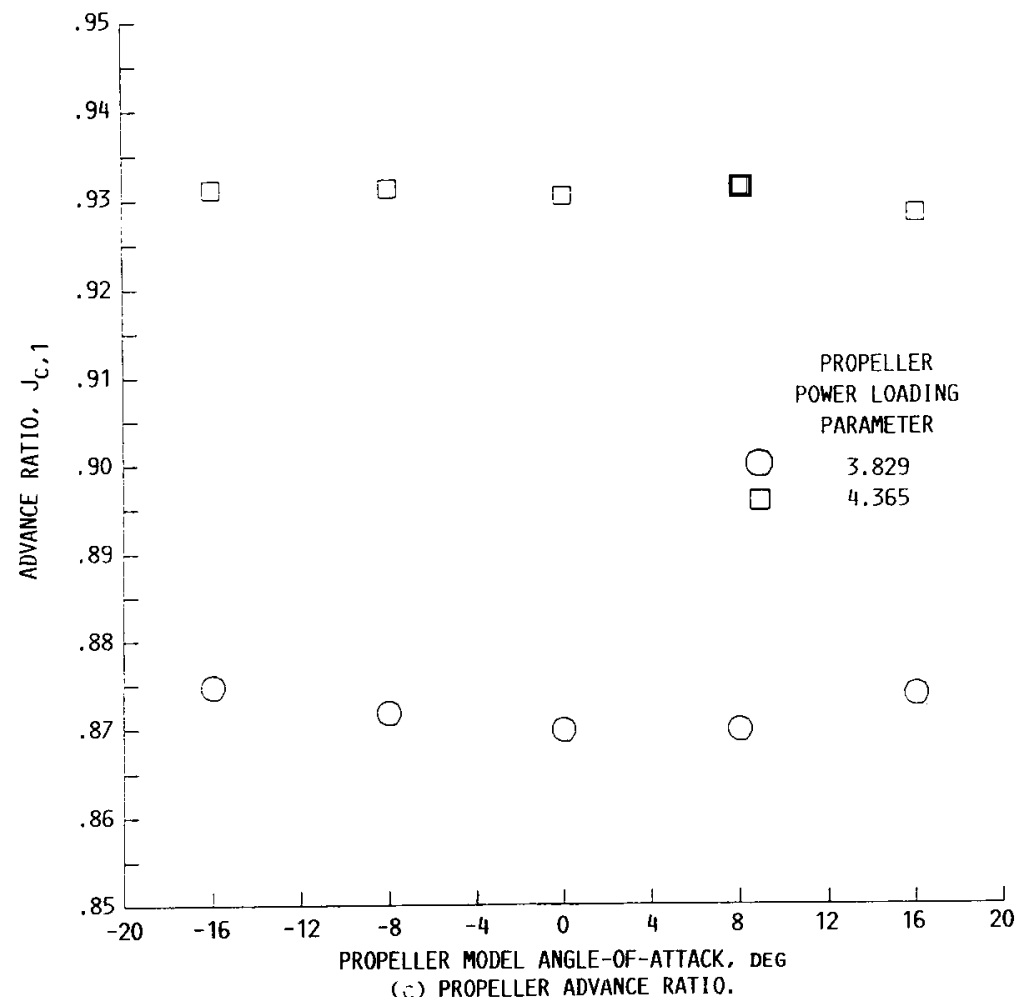

(c) PROPELLER ADVANCE RATIO.

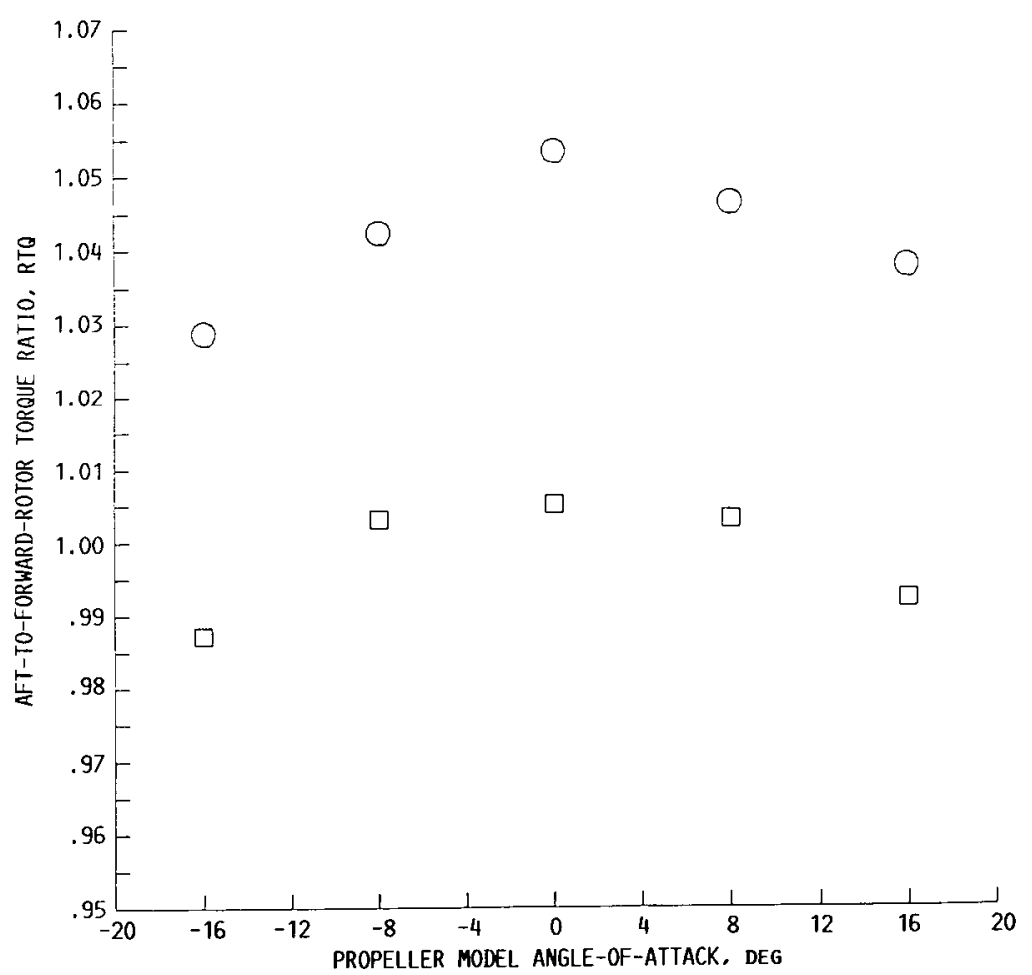

(d) PROPELLER AFT-TO-FORWARD-ROTOR TORQUE RATIO.

FIGURE 12. - CONCLUDED. 


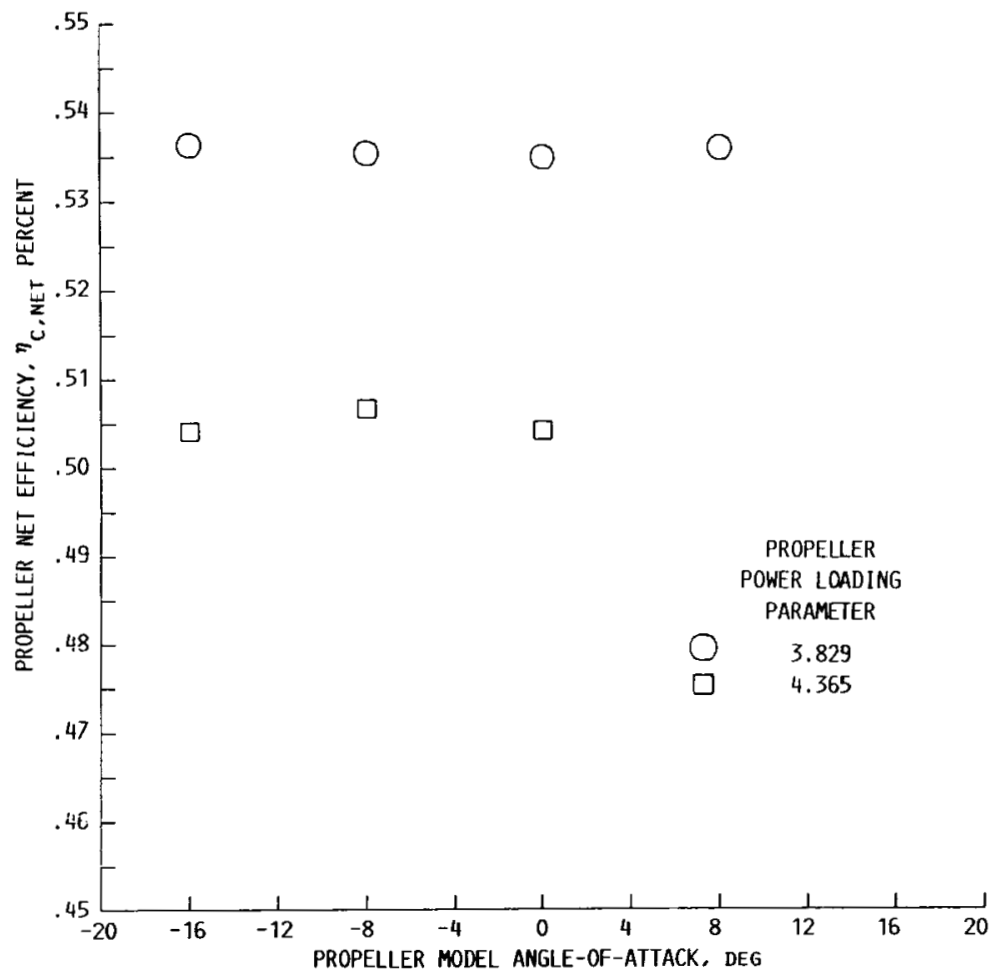

(a) PROPELLER TOIAL NET EFFICIENCY.

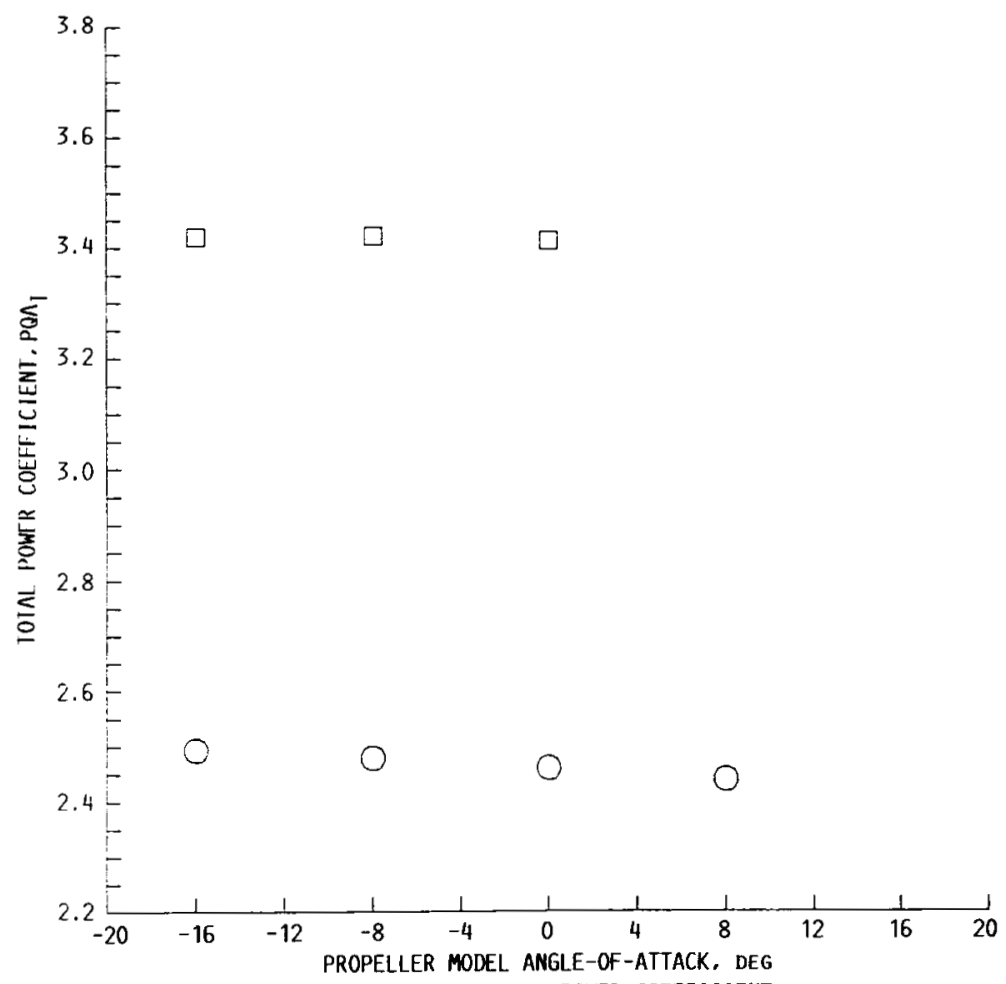

(b) PROPELLER TOTAL POWER COEFFICIENT.

FIGURE 13. - PERFORMANCE OF F7/A7 11/9 PROPELLER CONFIGURATION WITH ANGLE-OF-ATTACK WITHOUT PYLON OR FUSELAGE SIMULATORS AT CONSTANT TAKE-OFF TARGET POWER LOADING PARAMETERS 3.829 AND 4.365 AT MACH NUMBER 0.20 (PROPELLER BLADES ANGLES OF $36.4 / 36.5$ AND 41.1/39.4). 

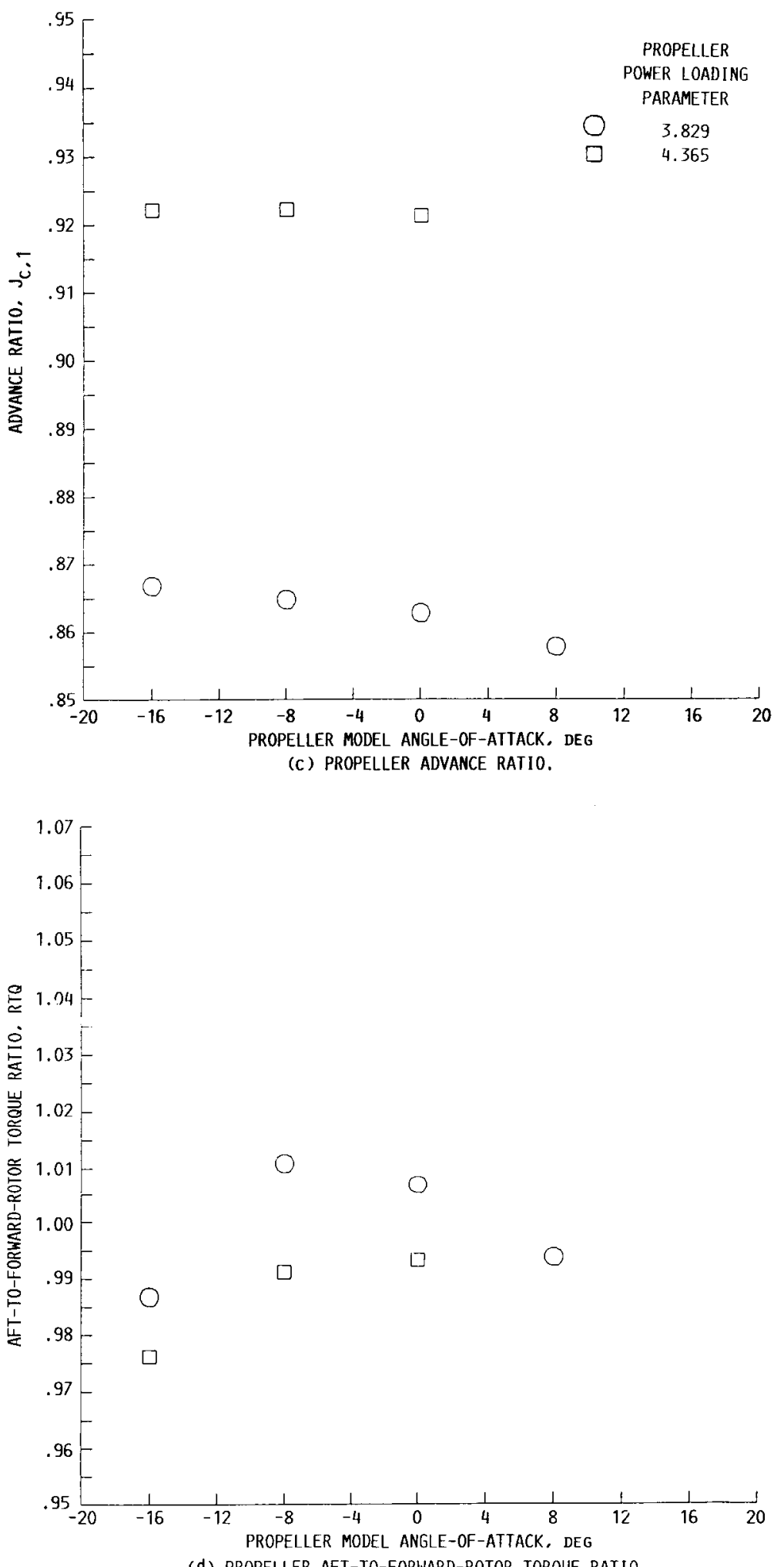

(d) PROPELLER AFT-TO-FORWARD-ROTOR TORQUE RATIO.

FIGURE 13. - CONCLUDED. 


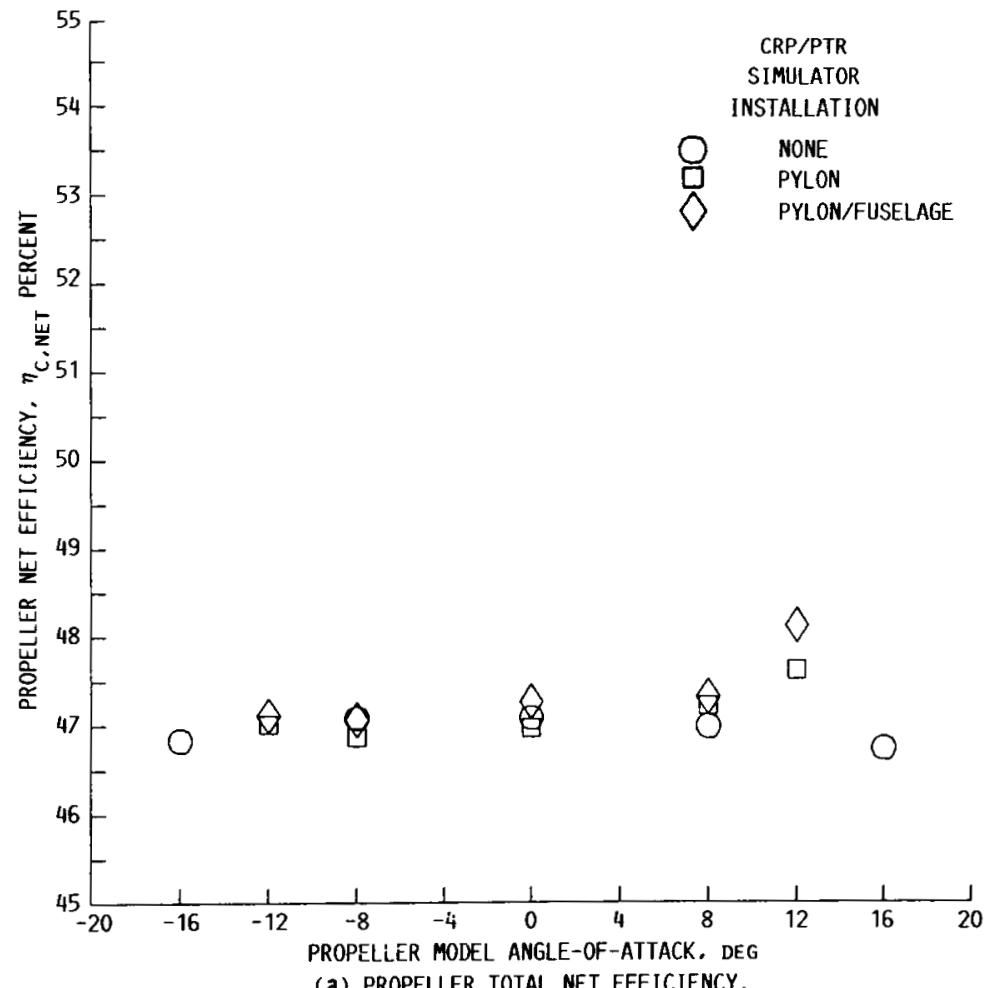
(a) PROPELLER TOTAL NET EFFICIENCY.

FIGURE 14. - PERFORMANCE OF F7/A3 11/9 PROPELLER CONFIGURATION HITH ANGLE-OF-ATTACK WITH AND WITHOUT PYLON AND FUSELAGE SIMULATORS AT A CONSTANT TAKE-OFF TARGET POMER LOADING PARAMETER OF 4.365 AT MACH 0.20 (PROPELLER BLADE ANGLES 41.1/46.4). 


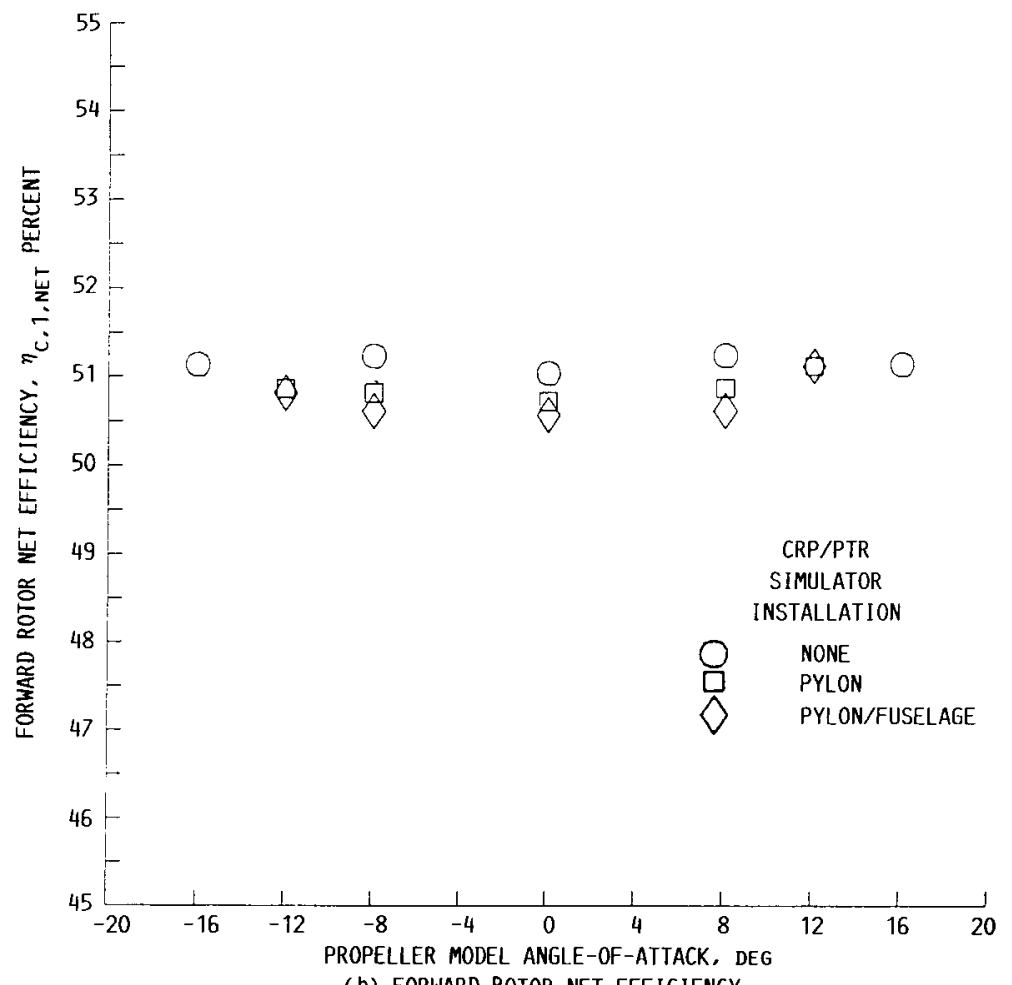

(b) FORWARD ROTOR NET EFFICIENCY.

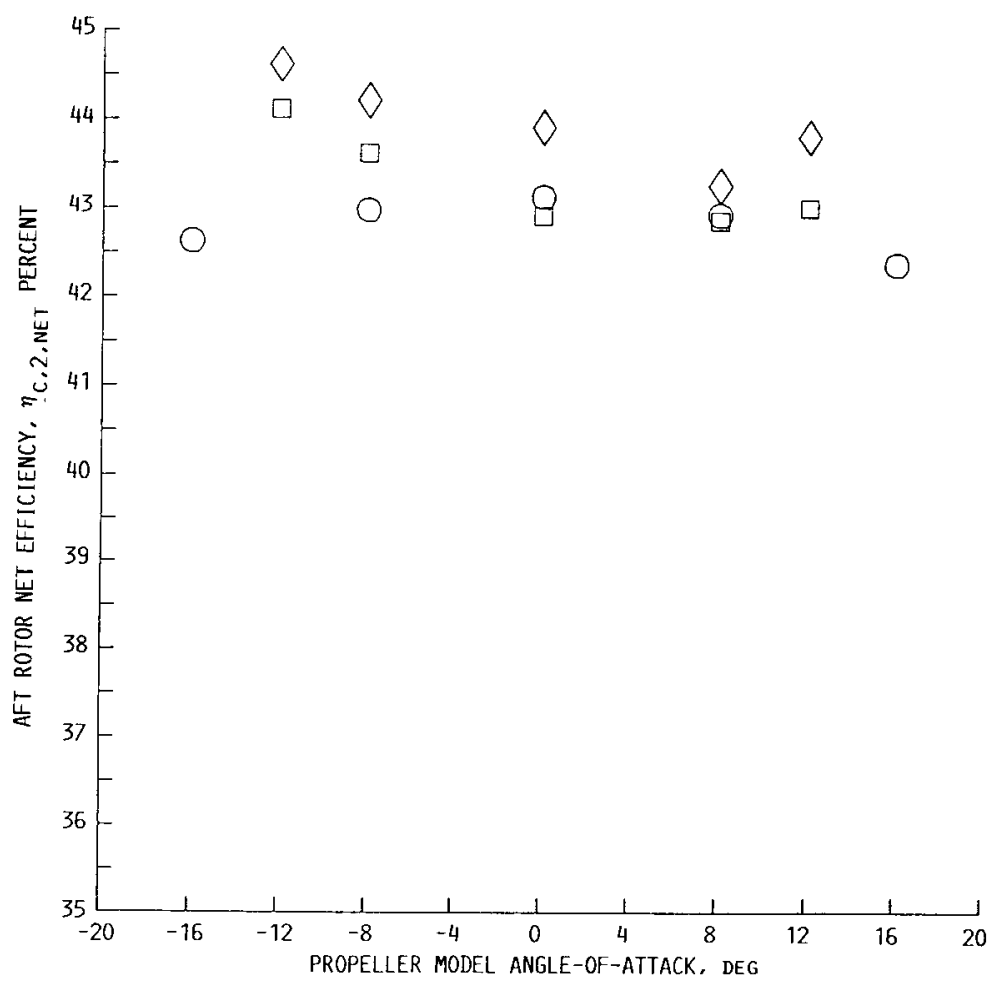

(C) AFT ROTOR NET EFFICIENCY.

FIGURE 14. - CONTINUED. 


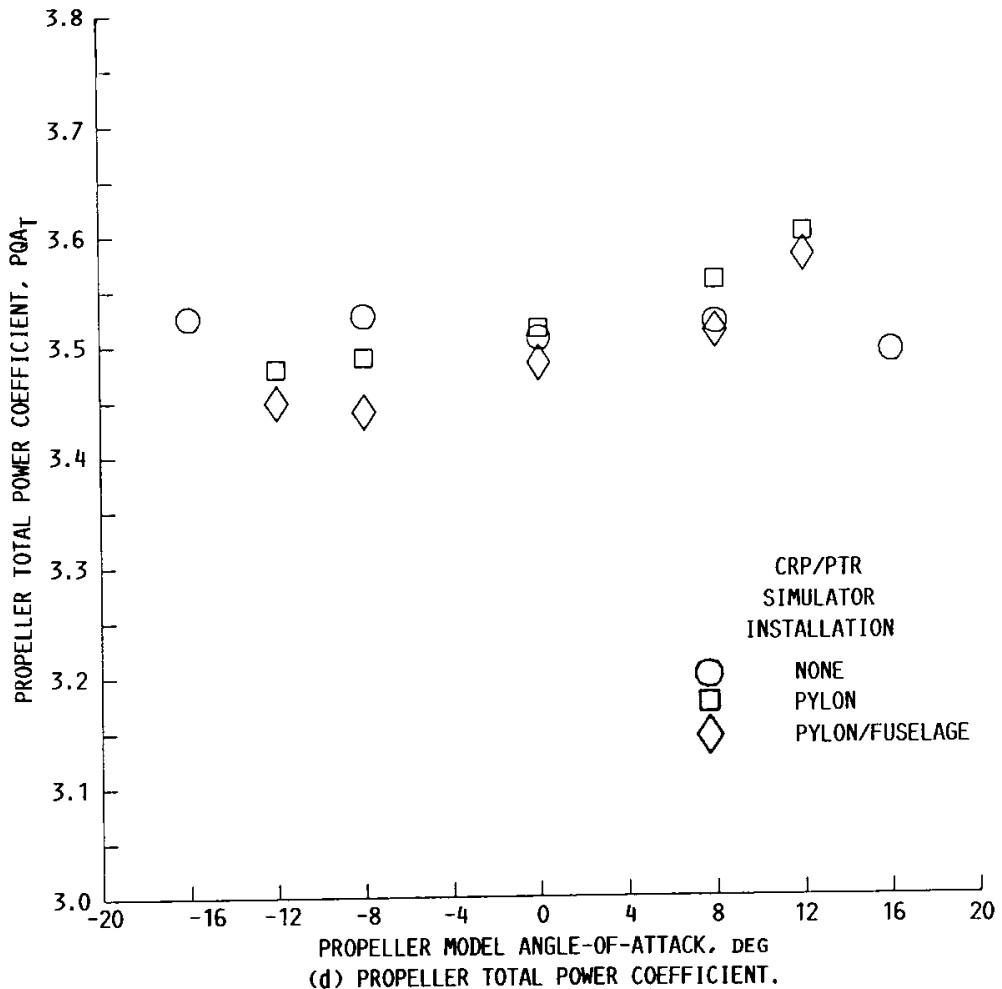

FIGURE 14. - CONTINUED. 


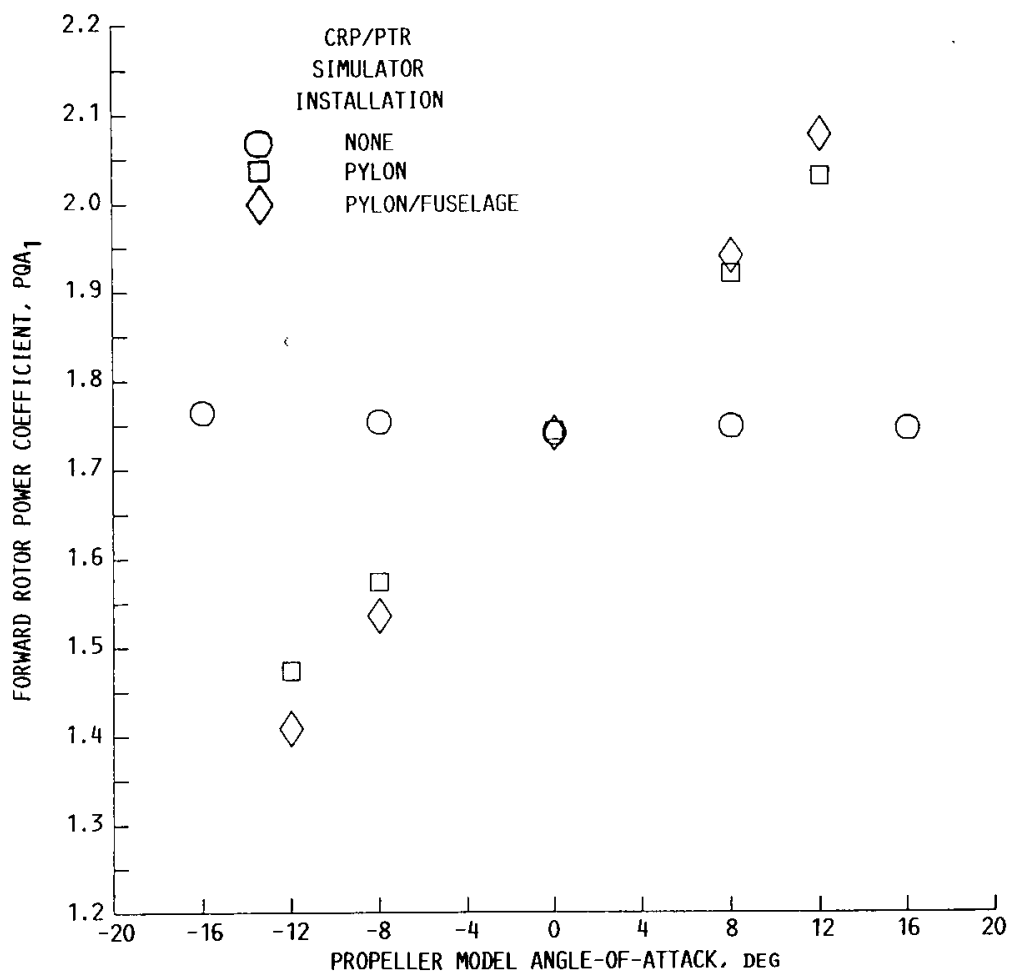

(e) FORWARD ROTOR POWER COEFFICIENT.

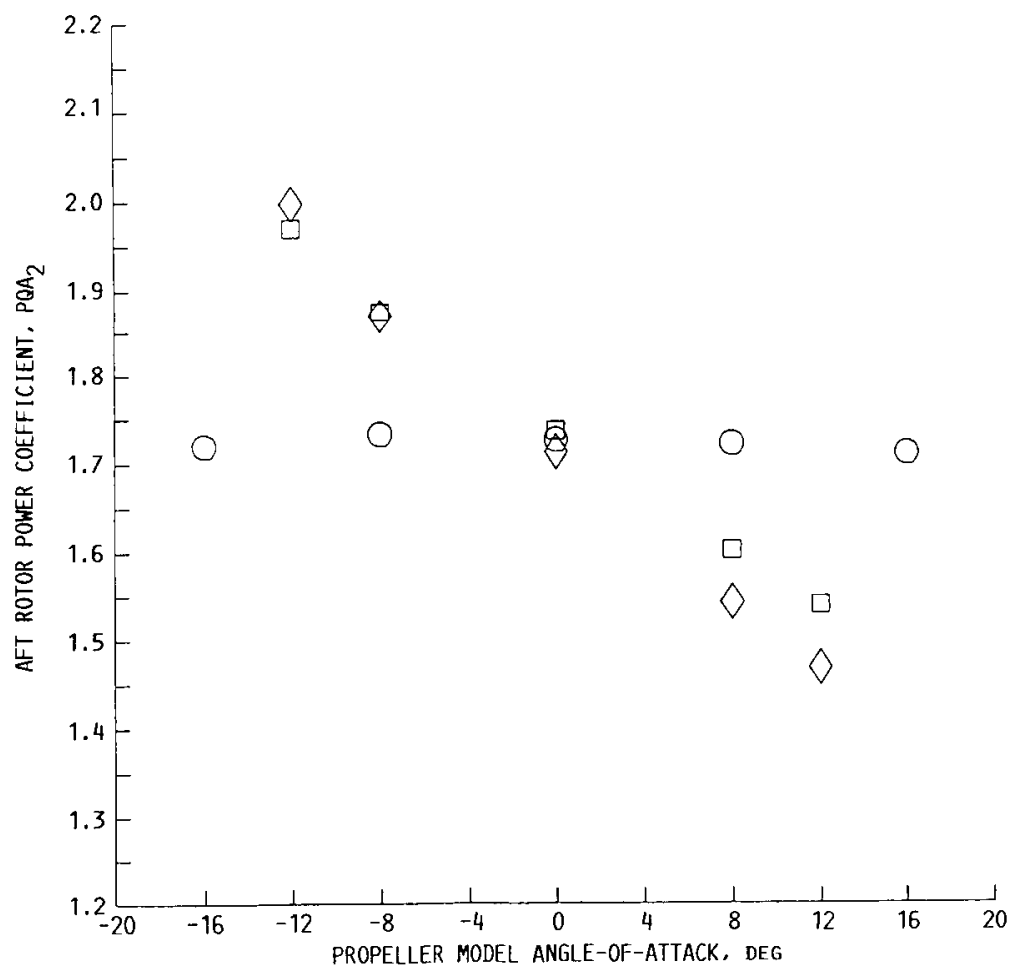

(f) AFT ROTOR POWER COEFFICIENT.

FIGURE 14. - CONTINUED 

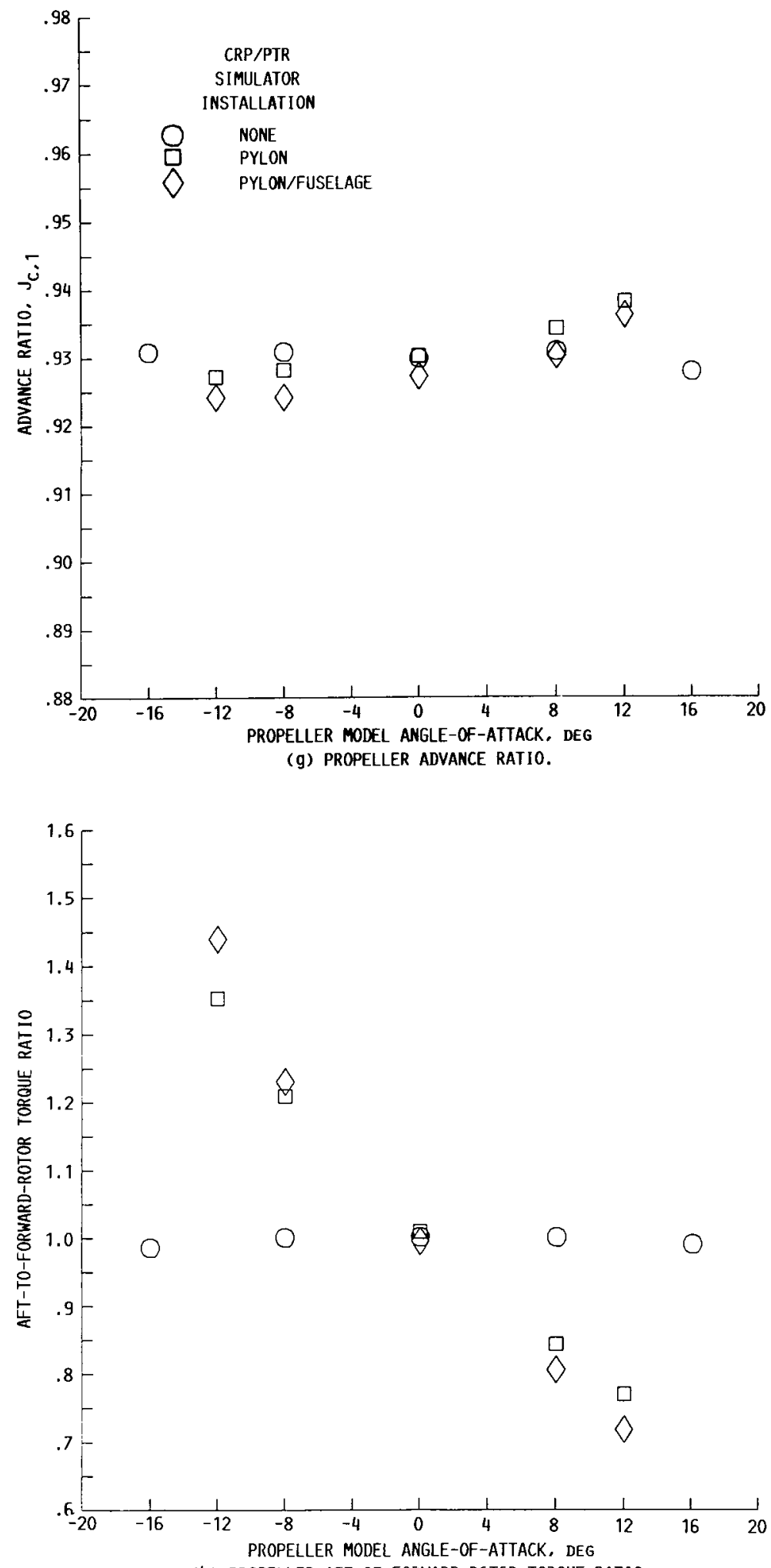

(h) PROPELLER AFT-OF-FORWARD-ROTOR TORQUE RATIO.

FIGURE 14 . - CONCLUDED. 


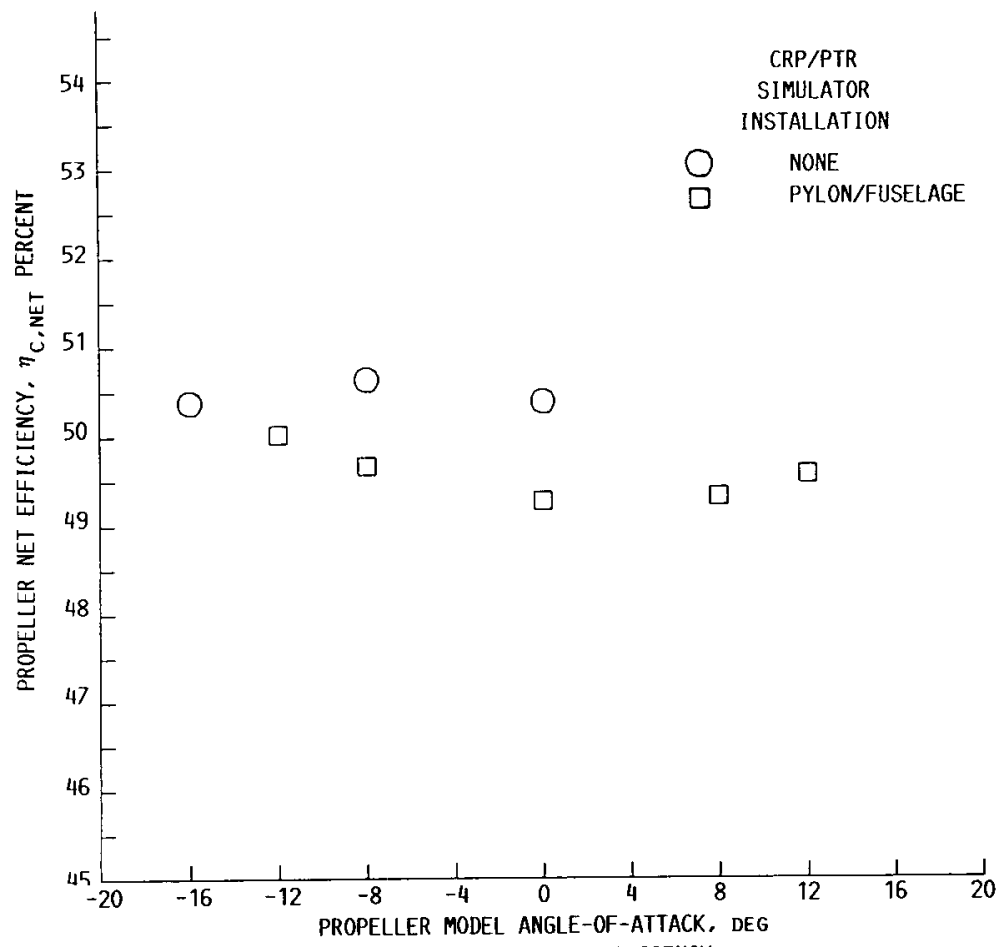

(a) PROPELLER NET EFFICIENCY.

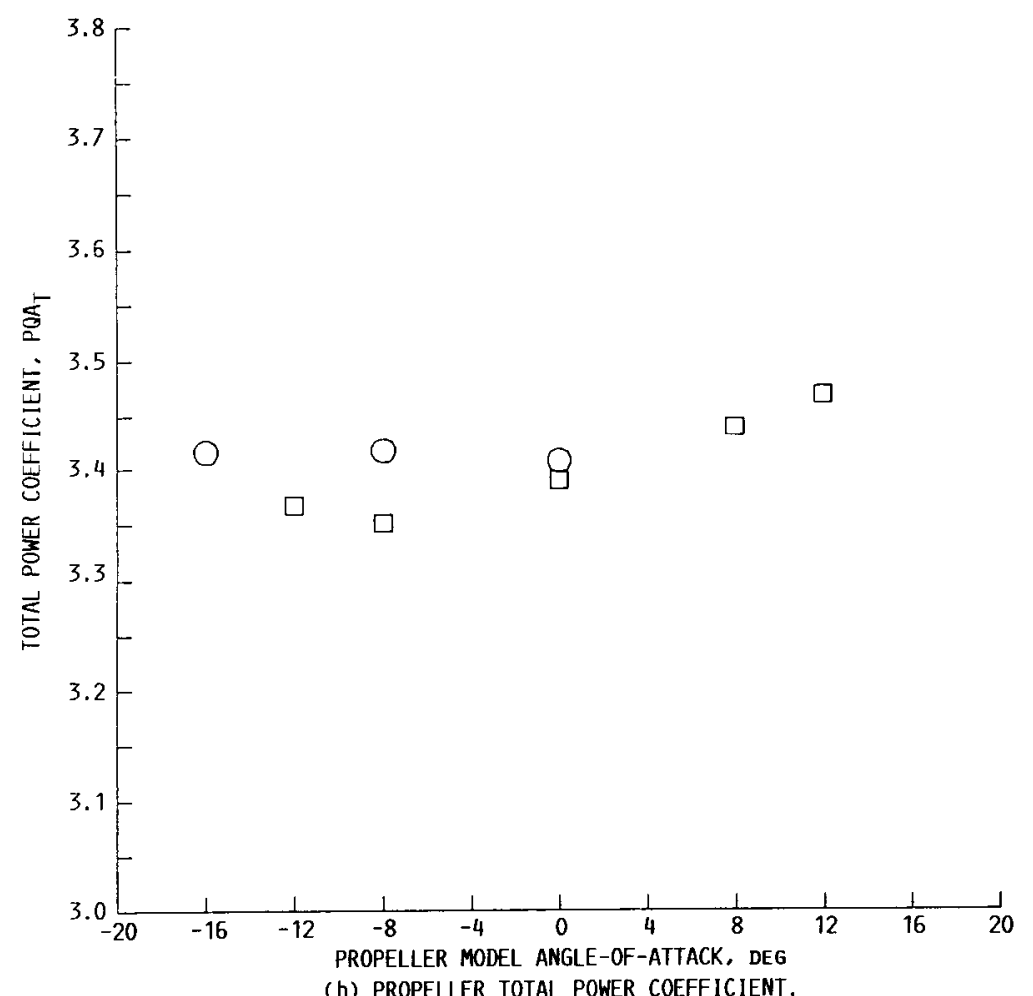

FIGURE 15. - PERFORMANCE OF F7/A7 11/9 PROPELLER CONFIGURATION WITH ANGLE-OF-ATTACK WITH AND WITHOUT PYLON AND FUSELAGE SIMUULATORS AT A CONSTANT TAKE-OFF TARGET POWER LOADING PARAMETER OF 4.365 AT MACH NUMBER 0.20 (PROPELLER BLADE ANGLES 41.1/39.4). 


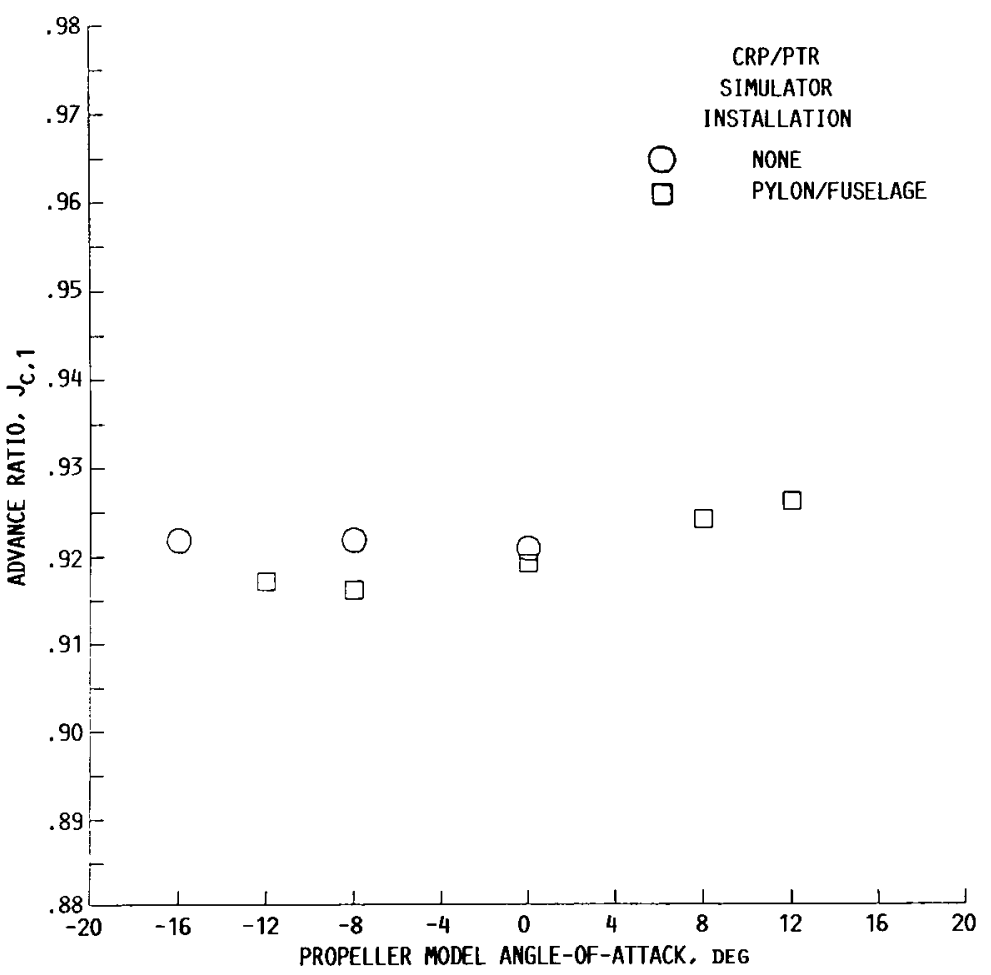

(C) PROPELLER ADVANCE RATIO.

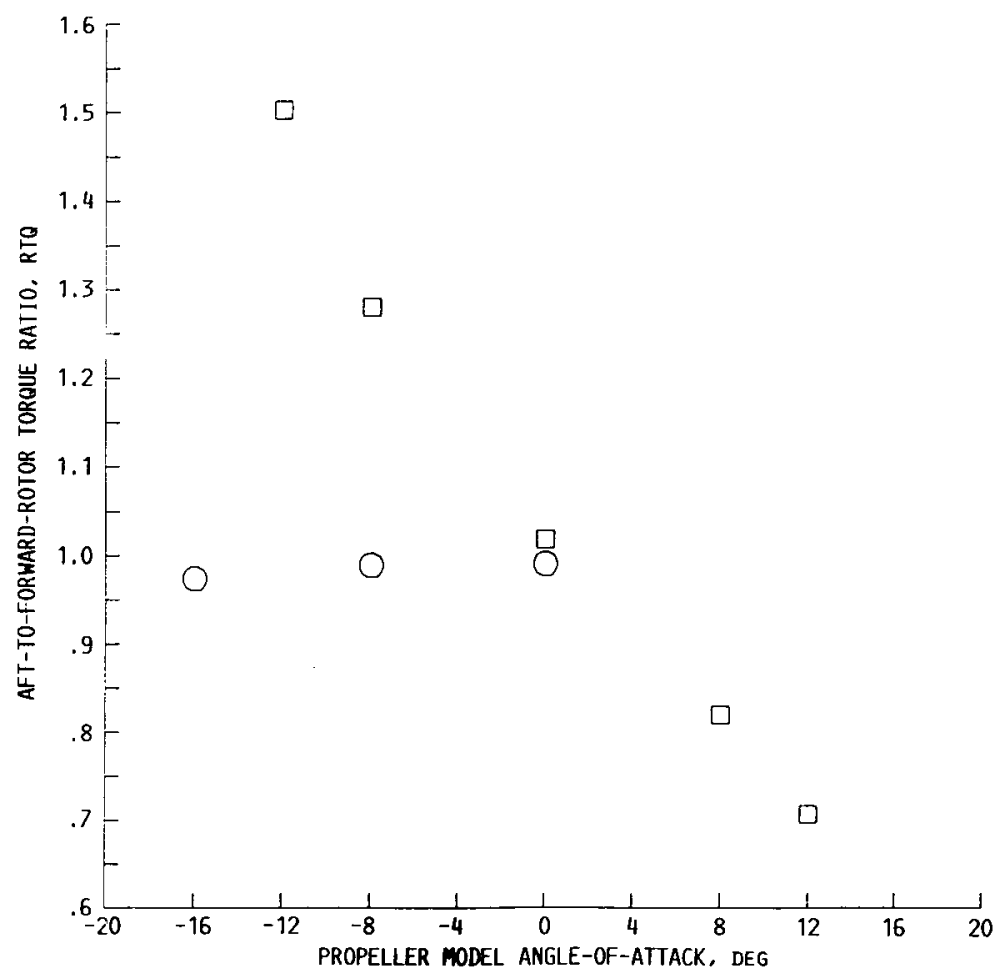

(d) PROPELLER AFT-OF-FORWAKD-ROTOR TORQUE RATIO.

FIGURE 15. - CONCLUDED. 


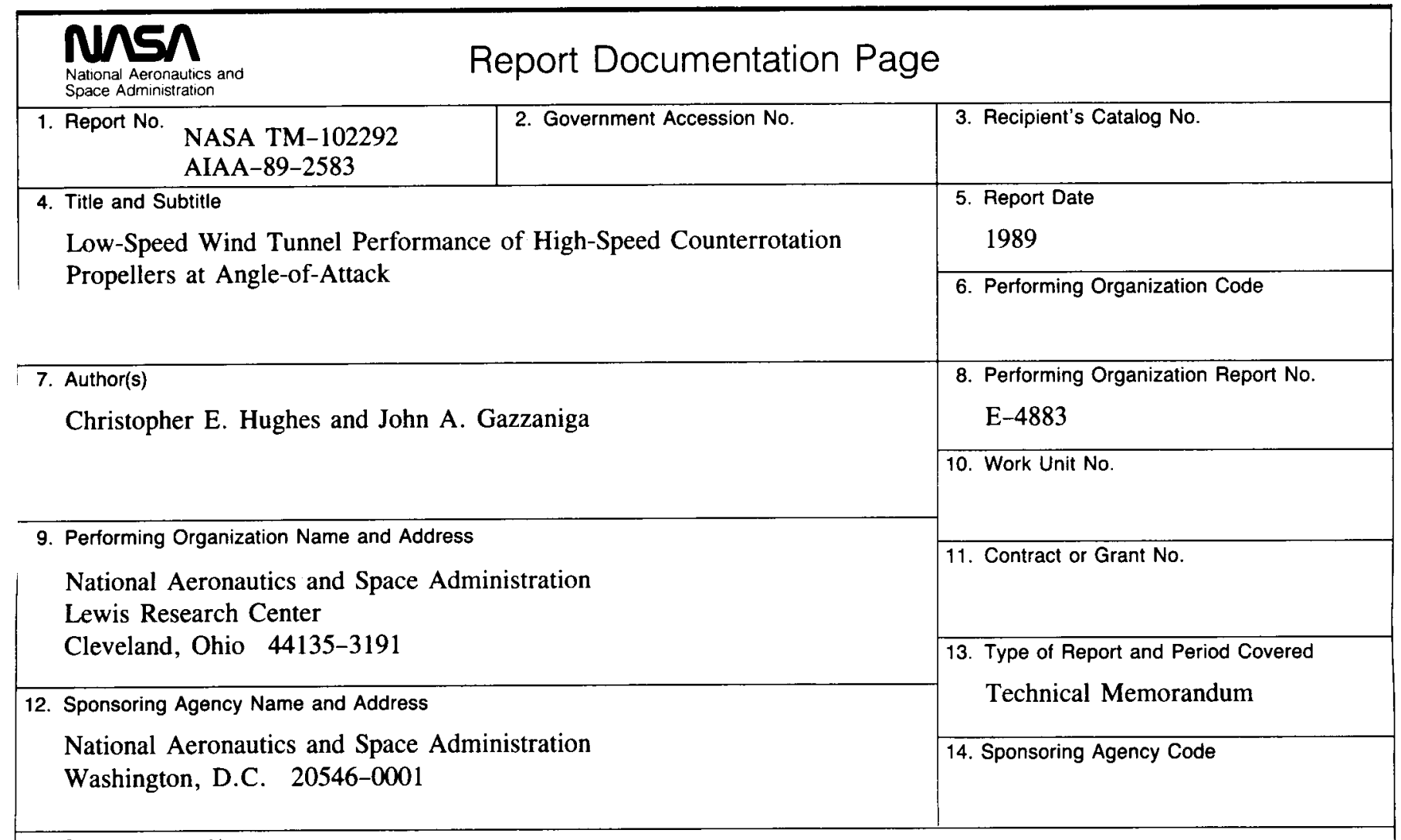

15. Supplementary Notes

Prepared for the 25th Joint Propulsion Conference cosponsored by the AIAA, ASME, SAE, and ASEE, Monterey, California, July 10-12, 1989. Christopher E. Hughes, NASA Lewis Research Center; John A. Gazzaniga, Sverdrup Technology, Inc., NASA Lewis Research Center Group, Cleveland, Ohio 44135.

16. Abstract

The low-speed aerodynamic performance characteristics of two advanced counterrotation pusher-propeller configurations with cruise design Mach numbers of 0.72 were investigated in the NASA Lewis 9 - by 15 -Foot Low-Speed Wind Tunnel. The tests were conducted at Mach number 0.20, which is representative of the aircraft take-off/landing flight regime. The investigation determined the effect of nonuniform inflow on the propeller performance characteristics for several blade angle settings and a range of rotational speeds. The inflow was varied by yawing the propeller model to angle-of-attack by as much as \pm 16 degrees and by installing on the counterrotation propeller test rig near the propeller rotors a model simulator of an aircraft engine support pylon and fuselage. The results of the investigation indicated that the low-speed performance of the counterrotation propeller configurations near the take-off target operating points were reasonable and were fairly insensitive to changes in model angle-of-attack without the aircraft pylon/fuselage simulators installed on the propeller test rig. When the aircraft pylon/fuselage simulators were installed, small changes in propeller performance were seen at zero angle-of-attack, but fairly large changes in total power coefficient and very large changes of aft-to-forwardrotor torque ratio were produced when the propeller model was taken to angle-of-attack. The propeller net efficiency, though, was fairly insensitive to any changes in the propeller flowfield conditions near the take-off target operating points.

17. Key Words (Suggested by Author(s))

Propfan; Counterrotation propeller; Wind tunnel; Low-speed; Angle-of-attack; Aerodynamic performance
18. Distribution Statement

Unclassified-Unlimited

Subject Category 02

19. Security Classif. (of this report) Unclassified

20. Security Classif. (of this page)

Unclassified

21. No of pages

47

22. Price* 